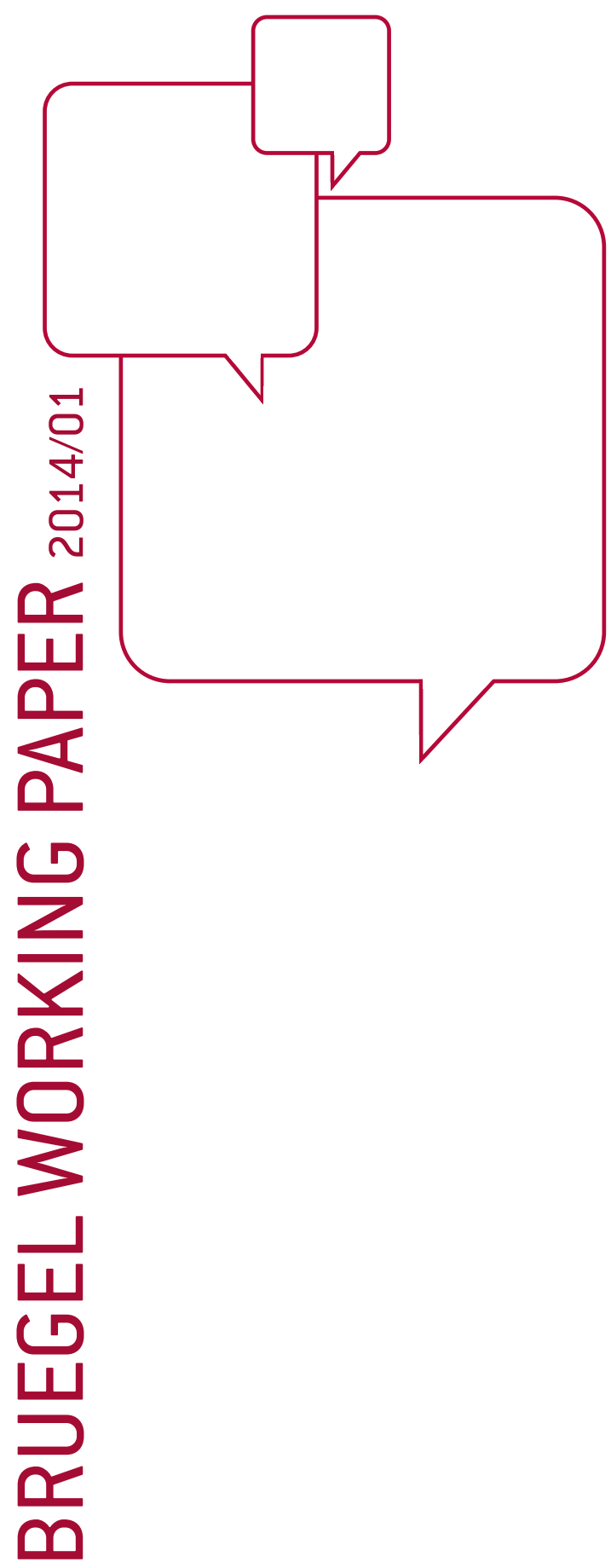

\title{
WHEN AND HOW TO
} SUPPORT RENEWABLES?

LETTING THE DATA SPEAK

GEORG ZACHMANN*, AMMA SERWAAH** AND MICHELE PERUZZI†

\author{
Highlights
}

- Low-carbon energy technologies are pivotal for decarbonising our economies up to 2050 while ensuring secure and affordable energy. Consequently, innovation that reduces the cost of low-carbon energy would play an important role in reducing transition costs. We assess the two most prominent innovation policy instruments (i) public research, development and demonstration (RD\&D) subsidies and (ii) public deployment policies.

- Our results indicate that both deployment and RD\&D coincide with increasing knowledge generation and the improved competitiveness of renewable energy technologies. We find that both support schemes together have a greater effect that they would individually, that RD\&D support is unsurprisingly more effective in driving patents and that timing matters. Current wind deployment based on past wind RD\&D spending coincides best with wind patenting. If we look into competitiveness we find a similar picture, with the greatest effect coming from deployment.

- Finally, we find significant cross-border effects, especially for winddeployment. Increased deployment in one country coincides with increased patenting in nearby countries.

- Based on our findings we argue that both deployment and RD\&D support are needed to create innovation in renewable energy technologies. However, we worry that current support is unbalanced. Public spending on deployment has been two orders of magnitude larger (in 2010 about $€ 48$ billion in the five largest EU countries in 2010) than spending on RD\&D support (about $€ 315$ million). Consequently, basing the policy mix more on empirical evidence could increase the efficiency of innovation policy targeted towards renewable energy technologies.

* Research Fellow at Bruegel. ${ }^{* *}$ Research Fellow at WZB, Berlin. $\dagger$ Research Assistant at Bruegel. The authors gratefully acknowledge research assistance from Nicholas Schöll. This work was supported by the SIMPATIC project (www.simpatic.eu), grant agreement number: 290597, under the European Union's Seventh Framework Programme. 


\section{Introduction}

All developed countries have been putting in place a number of policies to support renewable energy technologies for more than a decade and will continue to do so in the foreseeable future. The corresponding policies differ widely in scale, scope and design of legislation. However, none of the existing approaches is undisputedly accepted as effective and efficient. Hence, quantitatively benchmarking the different approaches is useful for structuring the discussion and identifying efficiency potential. To do this, we will first introduce the different rationales why to support renewables. We will than argue the most important policy to support them is to promote innovation in order to reduce the cost of a large scale deployment of yet uncompetitive technologies. Then, we will focus on the balance and timing of two main policy areas to drive innovation: deployment support and (public) research development and demonstration (RD\&D) spending. We argue that numerous countries introduced deployment support and RD\&D spending but that the allocation of funds between the two and timing resemble a 'shot in the dark'. Based on this motivation we will analyse a 28 country panel to determine which menus of policies are most successful in driving innovation. Finally we will draw policy conclusions.

\subsection{Why support renewables?}

Renewable energy technologies have been publicly supported for several decades but the reasons for doing so changed over time. Public support to the development of biofuels and renewable energy generation were part of the war effort that aimed at ensuring and diversifying energy supplies ${ }^{1}$ and providing technical solutions for warspecific purposes ${ }^{2}$ during the first and second world wars. The oil crises in the 1970 s brought about substantive programmes for RD\&D of photovoltaic cells and wind turbines in Europe and the US, as one tool to reduce dependence from Arab oil suppliers and shielding Western economies from high and volatile oil prices. The argument of renewables as a means to reduce import-dependency reappeared in the European public debate with the Ukrainian-Russian and Belarus-Russian 'gas wars' and the increasing oil and gas prices in the 2000 s. With the Club of Rome report in 1972, the narrative on the finite nature of energy resources received high public attention. The argument became somewhat side-lined in the public debate in the phase of low resource prices in the 1980s but re-emerged with the 'peak oil' debate in the 2000s. It can be found as one rationale for public support for renewable energy technologies in numerous public documents. One side-benefit claimed for renewables is that, by replacing power production in fossil plants, they reduce pollution (NOx, SOx, VOCs, etc.) that has negative health and/or environmental externalities ${ }^{3}$. Since the 1970s, the awareness of anthropogenic climate change increased in the public debate. It culminated in the 1996 Kyoto Conference in which most developed countries committed to reduce greenhouse gas emissions. The International Panel of Climate Change (IPPC) reports reiterate that containing global temperature increase requires a reduction of emissions from fossil

\footnotetext{
${ }^{1}$ Eg half a million producer gas vehicles running on wood pellets were used in Germany during the war.

${ }^{2}$ Eg Ethanol production from potatoes for fuelling German rockets or wind power for decentralised electricity production.

${ }^{3}$ One example: http://www.bmu.de/fileadmin/bmuimport/files/pdfs/allgemein/application/pdf/ee innovationen energiezukunft bf.pdf (BMU 2011, p.13)
} 
fuels while the baseline scenario expects increasing emissions. Consequently, massive public support for renewable energy technologies was rolled out to replace existing fossil plants by yet uncompetitive renewable units in the short term and/or to reduce the costs of renewable energy technologies units to make them competitive in the long term. By the late 1990s the outlined narratives indicated that a growing market for renewable energy technologies will emerge. To anticipate this development, economic policy makers suggested supporting domestic renewable energy technologies in order to gain a competitive edge in this growing field (i.e. industrial policy). Furthermore, demand side polices in order to mitigate the economic crises of the $2000 \mathrm{~s}$ envisaged public investments in renewable energy technologies. Consequently, industrial and macro-economic policies became a further rationale for supporting renewables. Finally, the nuclear accidents of Chernobyl (1986) and Fukushima (2011) undermined the public acceptance of nuclear as a source of clean energy in some countries, making renewables the only acceptable source.

Table 1: Rationale for public renewable energy technology support

\begin{tabular}{|l|l|}
\hline Event & Rationale for public renewable energy support [RES ] \\
\hline WWI 1914-18 and WWII 1939-45 & Military use of renewable energy technologies \\
\hline Oil crises 1972 and 1979 & $\begin{array}{l}\text { Reduction of energy dependence, } \\
\text { shield economies from oil price shocks }\end{array}$ \\
\hline Club of Rome report 1972 & Prepare for the finite nature of energy resources \\
\hline 1996 Kyoto Conference & RES as a means to mitigate carbon emissions from energy production \\
\hline Since around 2000 & RES support as infant industry policy \\
\hline 2008 crisis & RES deployment as demand-side macroeconomic policy \\
\hline 1986 Chernobyl, 2011 Fukushima & RES as a means to replace nuclear reactors \\
\hline Side benefit & RES to reduce pollution (NOx, SOx, VOCs, ... ) from fossil plants \\
\hline
\end{tabular}

So we conclude that several different rationales have been used to justify past and present support for renewable energy technologies ${ }^{4}$.

\subsection{How to support renewables?}

Already in the past, renewable energy technologies such as hydropower and geothermal energy have been widely used where they were competitive with other energy sources. Close-to-competitive technologies such as small hydropower plants were introduced in the market by preferential regulatory schemes and by pricing the externalities of fossil sources, e.g. through taxes and environmental regulations. However, competitive and close-to-competitive sources are in most countries unable to replace conventional plants in the volumes

\footnotetext{
${ }^{4}$ Most of the outlined reasons can be phrased as market-failure and hence a sensible case for public intervention can be constructed. See for example Riess et al[2012 p.83ff].
} 
necessary to fulfil the above-outlined purposes. Consequently, renewable energy technologies that are not (yet) competitive with conventional sources are required.

There are essentially three complementary strategies to replace fossil sources by renewable energy technologies that are currently not competitive. The first one is to substantially subsidise the current renewables until they are competitive. The second one is to make all undesired technologies uncompetitive either by taxation or regulation. And the third approach is to support innovation in renewable energy technologies in order to reduce their cost in the future.

Full-scale replacement of conventional sources by currently available renewable technologies (stimulated by subsidies and/or making conventional sources less competitive] would be prohibitively expensive ${ }^{5}$. Consequently, innovation is essential.

Literature has identified two interacting innovation policies: (i) encouraging 'learning-by-doing' through government supported deployment of yet uncompetitive technologies and (ii) public RD\&D as well as public support to private RD\&D.

\subsubsection{Deployment driven innovation}

In recent years both environment and economic research started focusing on endogenous technical change in the energy sector using learning curves. Arrow (1962) first introduced this theory showing that 'learning-bydoing' acted as a driver to reduce costs through different channels ${ }^{6}$. Costs of production are modelled as a function of the cumulated capacity. A learning rate can be derived which estimates the reduction of cost per doubling of capacity.

$$
\begin{aligned}
& c=\alpha * \operatorname{Cap}^{\varepsilon} \\
& L R=1-2^{-\varepsilon}
\end{aligned}
$$

where:

c Unit cost $[€ / \mathrm{KW}$ or $€ / \mathrm{KWh}]$

Cap Deployment (cumulative capacity or production, etc.)

$\varepsilon \quad$ Learning elasticity

LR Technology learning rate

\footnotetext{
${ }^{5}$ Thereby, the cost not only refers to the cost of the renewable energy technologies, but those of the entire system. For example, to achieve 100 percent of electricity generation from solar and wind technology substantial investments into storage, networks and demand response are necessary. To give one excessive example, a 10,000 $\mathrm{MW}$ solar installation in Germany ( 10 percent capacity factor] costing about $€ 10-20 \mathrm{bn}$ together with a 10,000 MW compressed air storage costing about $€ 10$ bn would be able to flexibly deliver electricity the same way as a 1,000 MW coal plant worth about $€ 2$ bn. To illustrate the magnitude of this effect, an economy wide shift from the current system to the outlined solar+storage system would increase electricity generation cost from less than 1 percent of GDP to about 10 percent.

${ }^{6}$ Jamasb and Köhler (2007) note that there have been, "early applications of learning curves, between 1930s and 1960s".
} 
Learning rates played a role for official policy documents as well as they are crucial part of a cost benefit analysis for renewable energy support (Jamasb and Köhler, 2007). Learning curves can provide a justification of subsidies exceeding the direct effect of climate change mitigation as they decrease the long term costs of new technologies. That is, deployment subsidies can lead to innovations in this sector which are more important than the direct reduction of green house gas (GHG) emissions in terms of social welfare (van Benthem et al, 2008).

\subsubsection{RD\&D driven innovation}

The main purpose of RD\&D is to generate innovations. Hence, it is little surprising that RD\&D spending leads to innovations that can be measured in terms of patents. For example, Gurmu and Pérez-Sebastián (2005) develop a 'patent production function' based on R\&D and lagged R\&D. They find that the (semi)elasticity of patents ranges between 0.4 and 0.7 suggesting decreasing return to scales ${ }^{?}$. As the current year accounts for over 60 percent of total R\&D elasticity, they conclude that R\&D impacts patenting at an early stage of the R\&D sequence.

Public RD\&D spending on particular technologies is also deemed to create innovations ${ }^{8}$. For example, Braun et al (2010) find that public RD\&D expenditure stimulates innovation in renewable energy technologies.

\subsubsection{A combination of deployment and RD\&D is driving innovation}

Based on earlier literature Wiesenthal et al (2012) present a two-factor learning curve model that disentangles two of the most important learning factors: learning by doing and learning by researching. The latter describes the relationship between the accumulated knowledge stock and production costs. For a given technology $t$ and time period $y$, the curve can be described as follows:

$$
C_{t, y}=a Q_{t, y}^{-\alpha} K S_{t, y}^{-\beta}
$$

where:

C Costs of unit production ( $€ / W]$

Q Cumulative Production (W)

KS Knowledge stock (here: approximated through R\&D investments, $€$ )

$\alpha \quad$ Elasticity of learning by doing

b Elasticity of learning by researching

a Normalisation parameter with respect to initial conditions

Soederholm and Sandqvist (2007) use a two-variable model using deployment and R\&D to estimate the effectiveness of different subsidy schemes. They show that learning rates depend crucially on the specification

\footnotetext{
${ }^{7}$ Similar to Hall et a/ (1986) who analysed data set from the seventies with similar models.

${ }^{8}$ This is despite crowding-out effects of private RD\&D spending. See for example Popp [2002).
} 
used. Quantifying effects remains difficult and the authors stress that simultaneity can lead to possible biases as for example reduced costs can lead to higher deployment.

Lindman and Söderholm (2012) review 35 studies on learning rates for wind power and warn that results are econometrically spurious in most empirical estimates. They argue that more attention should be paid on "learning and knowledge spillovers in the renewable energy field, as well as to the interaction between technology learning and R\&D efforts".

Koseoglu et al[2013] discuss the allocation of subsidies to either R\&D or market application. Their conclusion is that R\&D is underused compared to market application subsidies. A possible reason could be that short term effects of deployment are more visible than R\&D and therefore favoured by policy makers. However, too high deployment subsidies can induce lock-in into a (short-term) cost efficient technology preventing the development of other technology with higher long-term potential. Additionally, large subsidies can distort market incentives in a way that there is no net reduction in fossil energy use as the production of renewable energy units is very energy intensive. Public R\&D on the other hand can fill the knowledge gaps covering areas which would not profitable for private R\&D. In the US, states with transparent and openly available public R\&D also attracted significantly more private R\&D and venture capital in the respective sector (Koseoglu et al, 2013).

The model can be extended with additional variables to account for other factors that drive technological change $^{9}$. Johnstone et al (2008) conduct a panel regression across 25 countries between 1978-2003 for renewable energy patents showing that with respect to patent activity taxes, obligations and tradable certificates are the only tools statically significant. The estimations exhibit that R\&D spending is more effective for wind technologies whereas solar technologies are better supported by price incentives. Furthermore, stronger environmental legislation leads to more patents with heterogeneity across technologies: obligations and tradable certificates are most important for wind energy, which can be explained by the cheapest form of renewables hypothesis. According to their findings, solar energy on the other hand requires more direct investment support. Nonetheless, Johnstone et al (2008) argue that in general most patent estimates are flawed due to country heterogeneity and time trends.

Bettencourt et al (2013) explain the production of new energy patents in terms of new R\&D investments and expanding markets based on a Cobb-Douglas production function. They find that 'most technologies show greater sensitivity to market growth than to public R\&D investments though for wind the two contributions are similar'.

\footnotetext{
${ }^{9}$ Popp (2002) argues that the knowledge stock and the price of energy are important drivers of innovation in renewable energy technologies.
} 
Summing up, literature provides some evidence of (i) decreasing returns to both, deployment and RD\&D in driving innovation and (ii) a potential positive interaction of the two policy measures. In addition, the price of the competing technologies matters. This would indicate that innovation is best driven by a combination of RD\&D and deployment. We summarise this interaction in Figure 2. Innovations that cause system cost reduction are driven by (1) a certain amount of initial (or basic) RD\&D that brings down the cost of the technology before the first unit is deployed, (2) learning-by-doing through the subsidised deployment of certain amount the technology, (3) a price on carbon making conventional forms of energy less competitive and (4) parallel RD\&D expenses in order to speed up the learning. Finally (5), the break even for the new technology is contingent on how well the negative externalities of the incumbent technologies are priced in.

If this model were a fair description of reality, there should be an optimal combination of RD\&D spending and deployment. In this case, one would expect that such an optimal combination is different for different technologies. The exact relationship is, however, impossible to determine ex ante. Nevertheless, ex-post analysis of existing support schemes should allow to learn on efficient timing and balance.

Figure 1: Schematic picture of cost reduction for renewable energy technologies

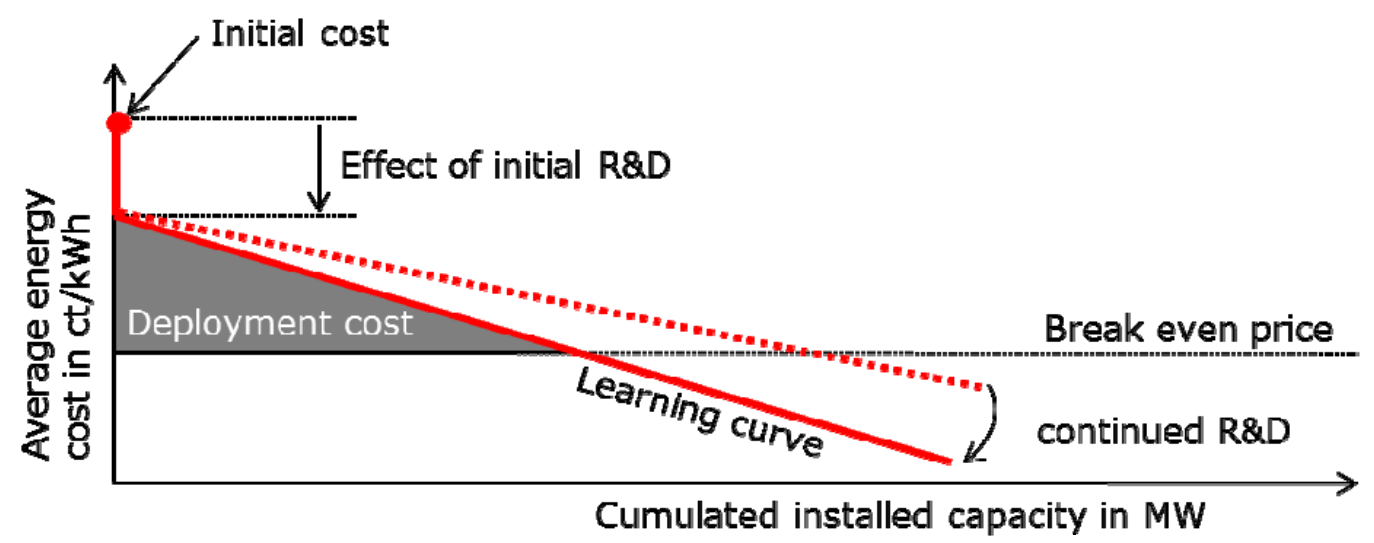

\subsection{Renewables support in practice}

Based on the rationales outlined in the first section (decarbonisation, import substitution, etc.), various support policies have been implemented with significant differences across countries and changes over time. Differences are partly explained by national differences in the prioritisation of the different aims. For example, if the goal is decarbonisation, then emission pricing might play a more prominent role. If the concern is on industrial policy, instead, RD\&D subsidies might be preferred. Finally, if security of supply is deemed to be more important, then deployment may be the focus. However, we cannot read the choice of a support mechanism or its intensity only as a techno-economic optimal response to the aforementioned challenges. In fact, every support mechanism produces substantial distributional effects, and institutional and information barriers are 
high. Consequently, without the complex political economy it is impossible to understand why different countries [and even regions] embarked on very different policy mixes.

There are different reasons why it is difficult to analytically identify optimal policy mixes: (i) the different rationales for renewables support, (ii) the numerous technology options, (iii) the substantial differences in the initial conditions, [iv] a wide continuum of combinations of support policies. According to Figure 2, countries like Germany and Italy spent on RD\&D less than 0.5 percent of the budget for public support to the deployment of renewable energy technologies. Thereby, to our knowledge no country applies an 'analytic' approach for determining the policy mix that best suits the rationales. This resembles a 'shot in the dark' approach, and its persistence is astonishing, given the magnitude of the corresponding public spending.

Figure 2: Deployment vs. RD\&D expenditure for wind and solar in 2010 in six EU countries [in € millions]

315

RDD $\square$ Deployment

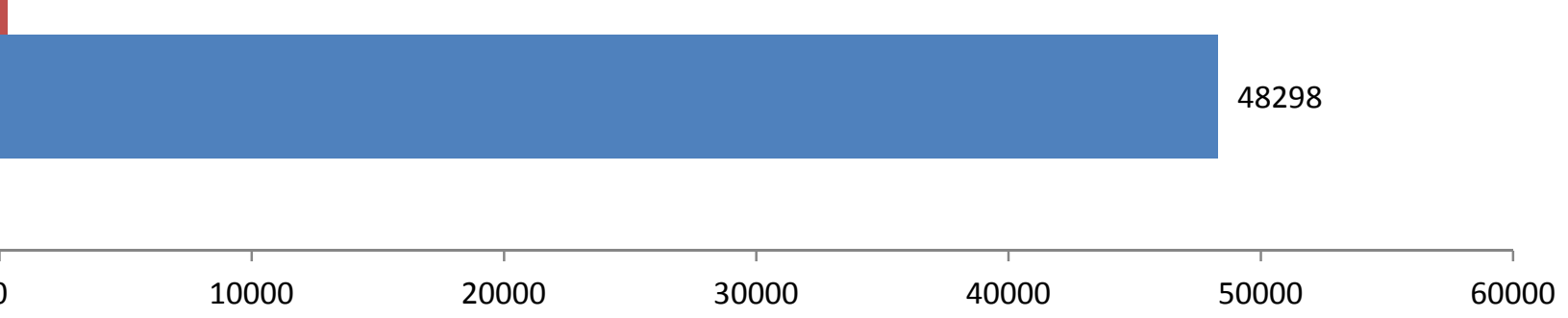

Source: Bruegel calculation based on IEA and datastream.

Note: Net deployment costs are calculated as the difference of the deployment $\operatorname{costs}^{10}$ and the net present value of the future electricity generated ${ }^{11}$. The countries are the five largest EU countries (DE,ES,FR,IT,UK) plus the Czech Republic (the largest Central East European country for which we have data)

\footnotetext{
${ }^{10}$ Deployment costs are calculated as the installation costs per MWe multiplied with the deployed capacity. The countryspecific costs per MWe are obtained from the "Projected Costs of Generating Electricity 2010" report of the IEA.

${ }^{11}$ The net present value of future electricity generated is calculated by discounting future revenues which can be obtained by projecting the yearly energy prices (we use the price of a 2013 futures contract) and production of the respective technology in the respective country (differences across countries arise because of varying hours of sun/wind per year as well as different energy prices). We assume a nominal interest rate of 10 percent.
} 


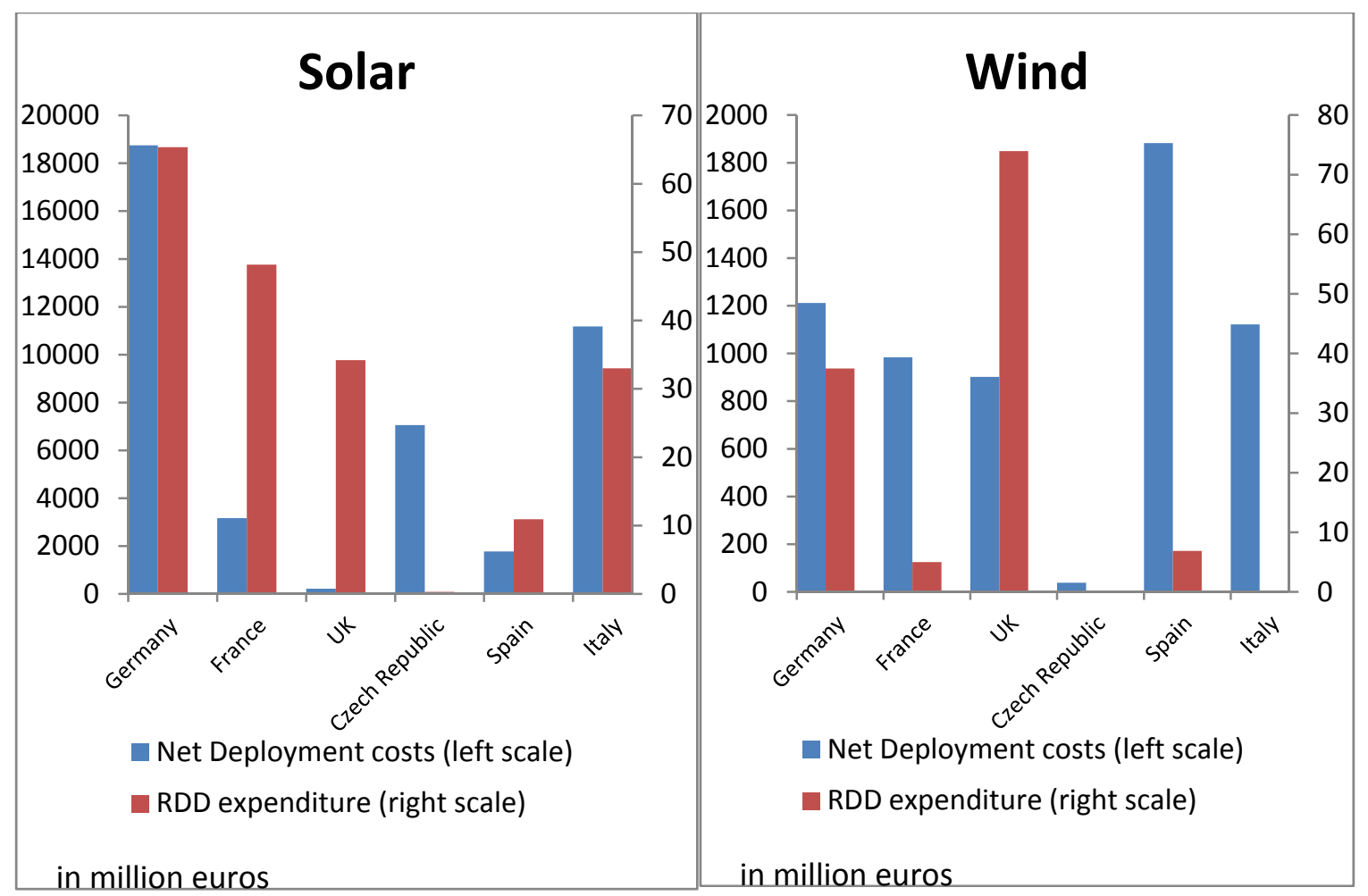

Source: Bruegel calculation based on IEA and datastream.

Note: Net deployment costs are calculated as the difference of the deployment costs and the net present value of the future electricity generated.

\subsection{Research question}

Our research question is based on the above argumentation that (i) there are different rationales for supporting renewables; (ii) for all rationales, long-term cost reduction is key. Therefore, supporting innovation in renewable energy technologies is the major policy to achieve each of the policy goals; (iii) literature has identified deployment policies and RD\&D spending policies as effective innovation policies; (iv) countries use a very heterogeneous set of balance and timing of the two policies.

The research question is whether innovation in certain renewable energy technologies (in our case wind and solar) can be best encouraged by a specific timing and balance of deployment policies and RD\&D spending ${ }^{12}$.

\section{Data}

We build a panel of 28 OECD countries, covering the time period from 1990 to 2010 . The main variables of interest - patent count, R\&D expenditure and deployment - are provided by the OECD and IEA statistical services. We focus on the two most prominent renewable energy technologies: wind power and photovoltaic solar energy. These two sources accounted for about 64 percent of newly installed capacities in 2012 in the EU, and

\footnotetext{
${ }^{12}$ le, we will not evaluate individual instruments [such as 'green certificates' vs. 'feed in tariffs'] or individual technologies (such as 'on-shore wind' vs. 'off-shore wind').
} 
accounted for roughly $?$ percent of total cumulative capacity by 2010 . We follow the OECD classifications of patenting and spending into these two categories ${ }^{13}$.

Patents in this data set refer to granted patents and the dates referred to are the priority date, which is the date used by patent examiners to establish novelty. In effect this is the date of invention. This allows us to focus on the innovative timing without complications due to delays in different legal systems. However, since the dataset only includes granted patents, some data in later years is still spotty as, for example, a patent filed and assigned a priority date in 2010 might only be granted in subsequent years.

Similar to the literature on learning curves, we use lagged deployment and RD\&D to explain technical change. The difference in our approach is that we proxy innovation by patents rather than costs. We consider the effects on patenting of (i) the knowledge stock, (ii) the deployment stock, (iii) technology spillovers, and (iv) country spillovers.

The knowledge stock of each technology is measured as the cumulated sum of annual patents in the corresponding technology. The deployment stock is the cumulated sum of deployed technology, measured in MW. We use different discounting factors $(0 \%, 5 \%, 10 \%, 20 \%)$ to account for the depreciation of the knowledge stock and the deployment stock over time. We account for technology spillovers by considering the impact of patenting and deployment in a given technology on the other technologies (i.e. patents and deployment in wind are included as control variables for the analysis in solar.) We also control for patenting and deployment in a broader range of renewables which includes solar thermal, geothermal, and wave energy. Country spillovers are taken into account by controlling for the deployment in the rest of the continent (e.g., one of the factors considered for explaining German patenting in wind energy is the deployment of wind power in Europe minus the German deployment). Furthermore, we also control for the deployment in all other countries weighted by the inverse distance. Here we use different distance measures, as provided by $\mathrm{CEPII}^{14}$.

\footnotetext{
${ }^{13}$ http://www.oecd.org/env/consumption-innovation/44387191.pdf.

${ }^{14}$ Mayer, T. \& Zignago, S. [2011] Notes on CEPII's distances measures : the GeoDist Database CEPII Working Paper 2011-25 -

See more at: http://www.cepii.fr/CEPII/en/bdd modele/presentation.asp?id=6\#sthash.ZEPLKOSm.dpuf.
} 
Figure 4: Solar and wind patents US and EU

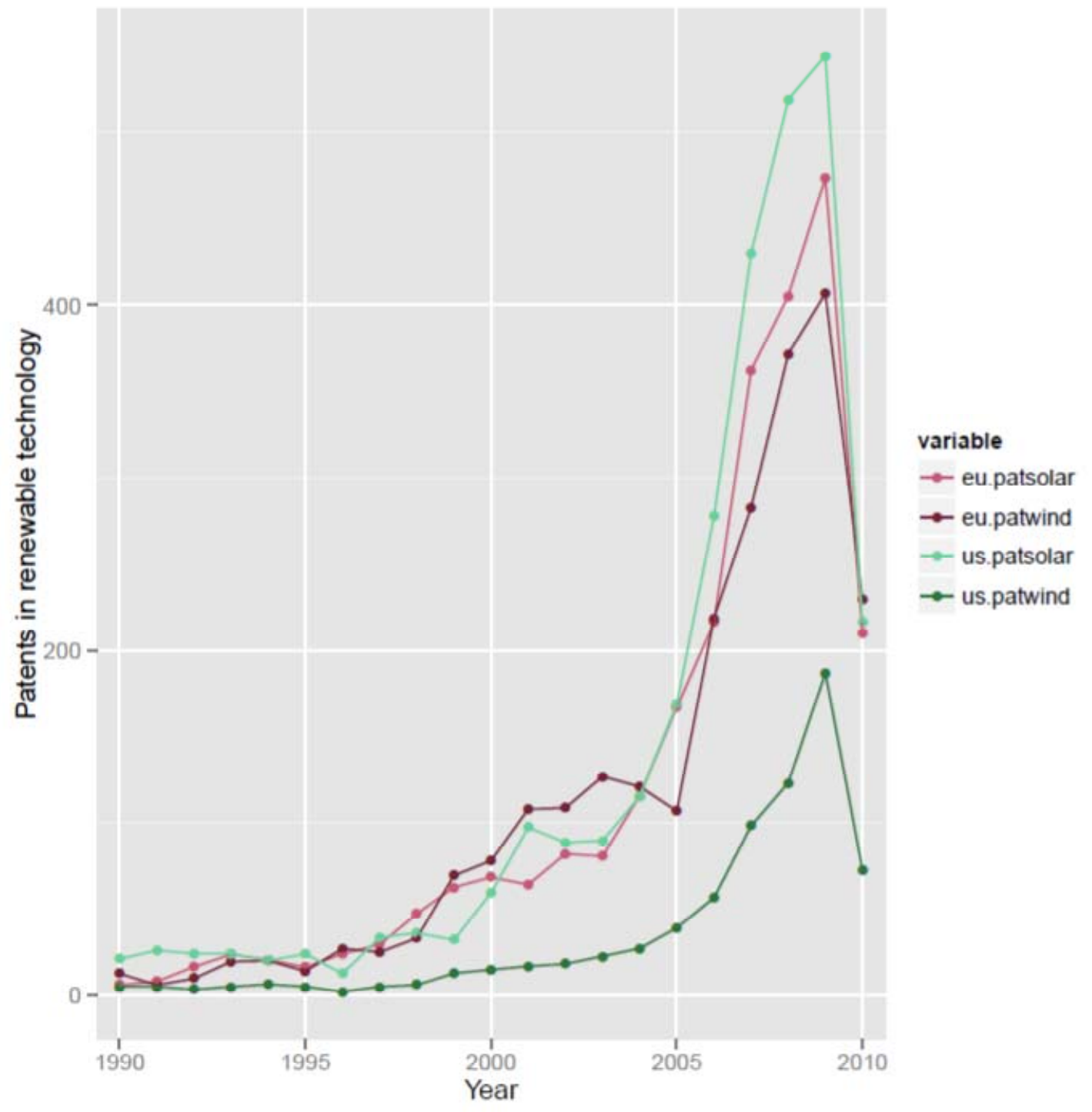


Figure 5: Solar and wind deployment in US and EU

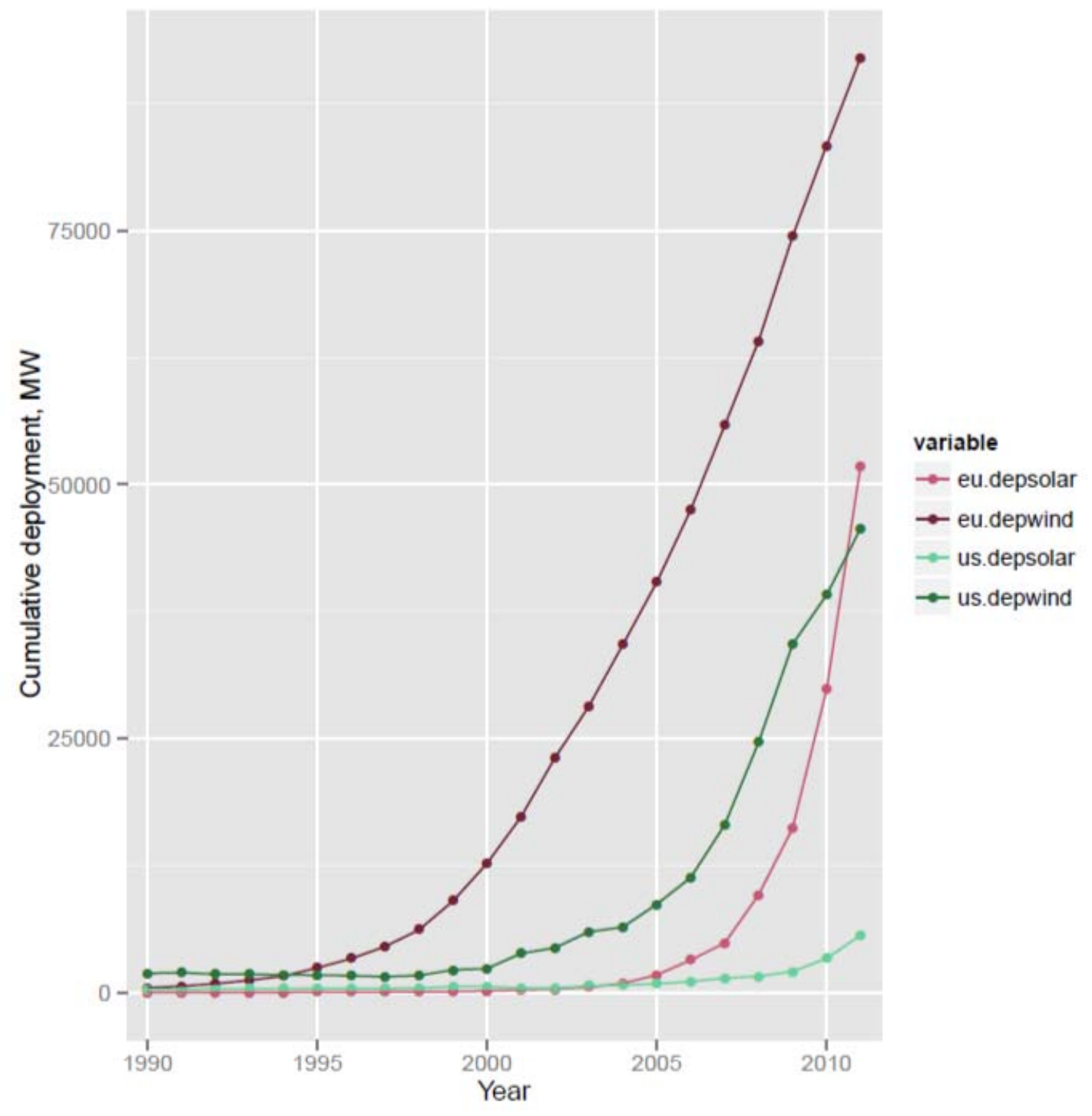

Despite the stronger patenting in solar, US solar deployment lags significantly behind US wind deployment (Figure 5). On the other side of the Atlantic, EU solar deployment is outpacing EU wind deployment from 2009 on - cumulated capacities stay still larger. 


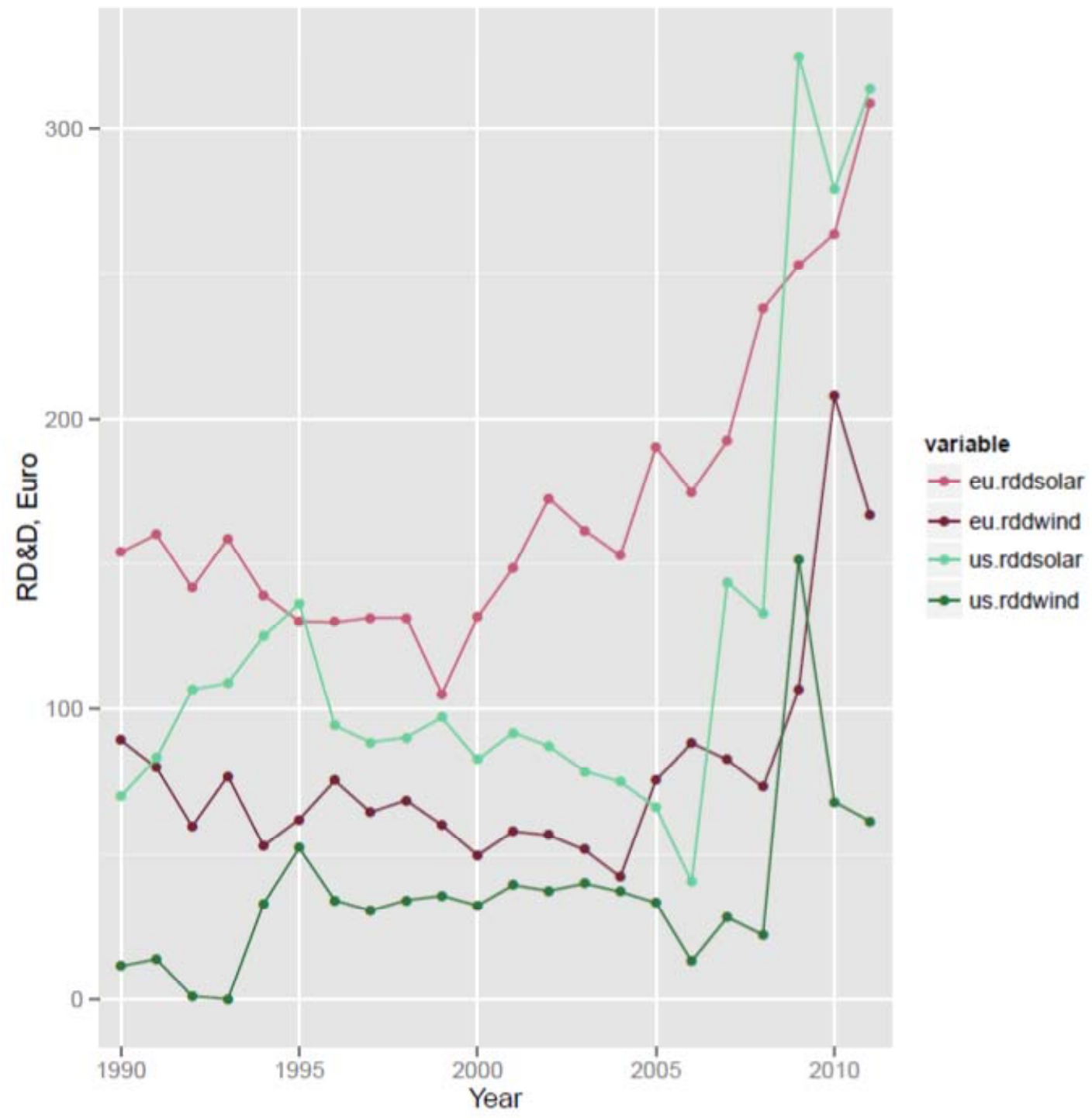

When we consider RD\&D (Figure 6), we do see a small increasing trend after 2005 that slightly echoes the increase in patenting. Perhaps unsurprisingly, given the patenting figures, RD\&D in solar is greater than in wind, lending support to a notion that connects RD\&D spending with actual innovation.

Finally, as an alternative measure of the relative progress individual countries did make in making solar panels and wind turbines produced in their county competitive on the global market, we use the revealed comparative advantage (RCA). In order to obtain an interpretable measure with a known distribution we use the ranking of the RCA-score for each country compared to our sample. To ensure the intuitive 'more is better', we invert the ranking, so that the worst country gets a 1 and the best country gets a score equal to the number of countries (28). To give an example, the US was a 'slightly above average' performer in exporting solar panels in the 1990s (inverse ranking score below 20), it became one of the most successful solar exporters in the early 2001-02 (inverse ranking above 20) before it started to constantly lose competitive edge in solar exports until 2011 (inverse ranking 12). 
Figure 7: Revealed comparative advantage position in wind and solar for selected countries, 1990-2011

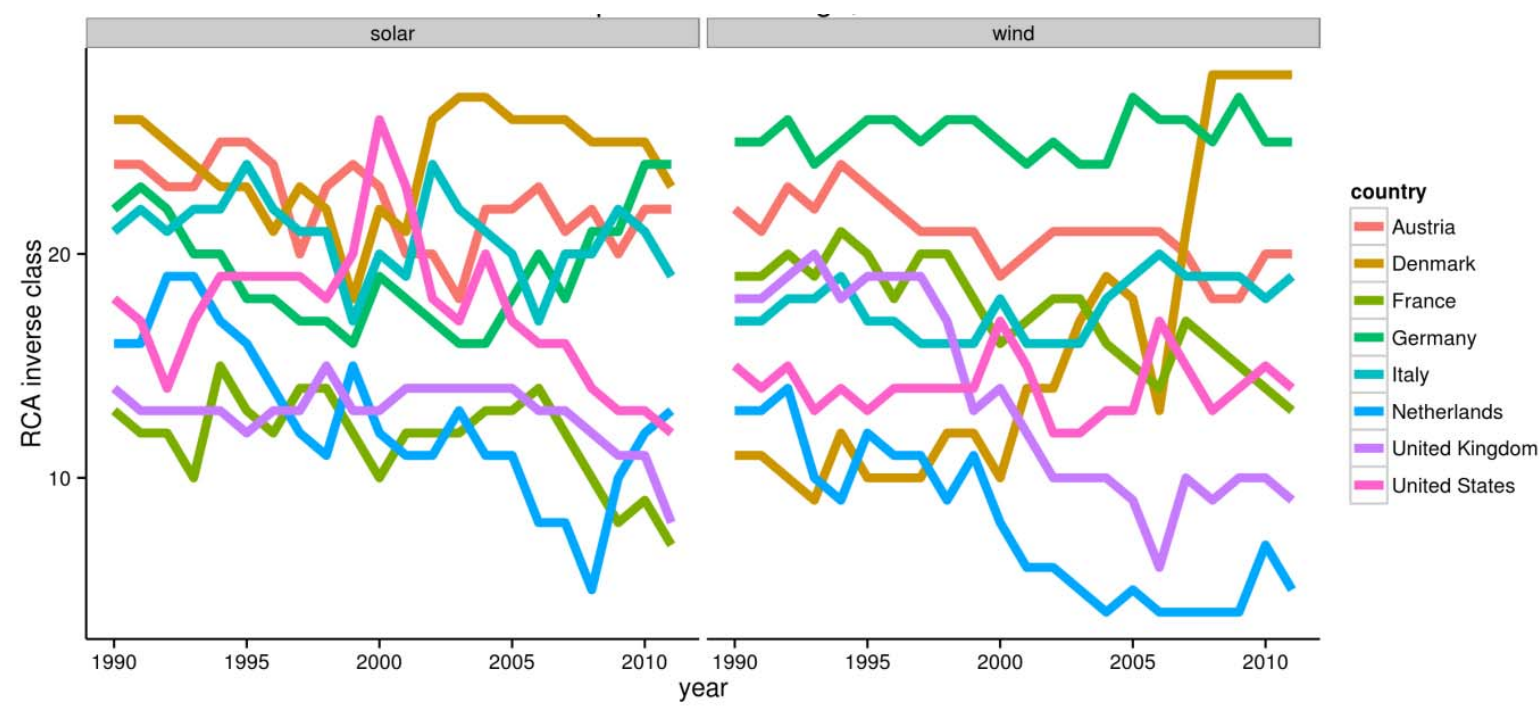

\section{Analysis}

We do not possess a theoretical model that explains patenting in a certain technology in a certain country based on past deployment, RD\&D spending and other variables ${ }^{17}$. While our prior belief is that both, deployment, RD\&D spending and their interaction have all a positive effect on patenting, it is unclear to us how fast the corresponding inputs might generate innovation and whether this effect is linear or not. Consequently we decided to rely on a data-driven approach to select the relevant variables, time lags, operations (such as the logarithm] and interactions. To select the explanatory variables included in our model we proceed in five steps. First, we create four 'derivatives' of each of the original variables (level, log, square root and square). Then we include the first five lags in the set of explanatory variables. Third, we include all possible partial sums of consecutive lags, such as the deployment in the past five years, or the RD\&D spending three-to-six years ago. Fourth, we include dummies for countries and years. Finally, we create all possible bilateral interaction terms between all these variables (original variables, derivatives, lags, partial sums and dummies). For example, one variable is the interaction of deployment in the last five years with the RD\&D spending three-to-six years ago. This gives us more than 47,000 explanatory variables.

A standard panel regression of 28 countries times 20 years based on about 47,000 explanatory variables (that are suffering almost perfect collinearity) is obviously unfeasible. To select the explanatory variables that are most useful in explaining the patenting in certain technologies we employ a penalised regression approach (see Tibshirani, R., 1996) ${ }^{18}$, the so-called 'Lasso'. Basically, instead of running an unconstrained optimisation problem (of SSR or likelihood), the Lasso does a constrained optimisation with a penalty. The Lasso is a

\footnotetext{
${ }^{17}$ To our knowledge, existing models like "one factor learning curves", "two factor learning curves" or Cobb-Douglas patent production functions are not based on theoretical models either.

${ }^{18}$ As patents are typically discretely scaled $[$ i.e., $1,2,3, \ldots]$ we base the regression on a Poisson model.
} 
particular case of shrinkage estimator. These are estimators that optimise on a restricted set of values for the coefficients of the variables. The penalty parameter can be chosen by the researcher, and controls how large this restricted set is. The particular form of the penalty function results in sets of different shapes. The Lasso penalty in particular results in subsets that have a corner at zero in all dimensions. The outcome is that the optimum is reached with many coefficients set exactly to 0 . Hence, by its construction the Lasso performs a variable selection. Thereby, the larger the lambda, the more restrictive the variable selection is and the smaller the set of non-zero coefficients. In addition to the variable selection, the coefficients for all non-zero variables have been shrunk. While other selection mechanisms that do not apply shrinkage may be unstable because they are affected by collinearity, the Lasso overcomes this issue by construction.

This allows for two interpretable outputs: first, the order in which the different explanatory variables are included in the regression - when reducing lambda - is meaningful. It gives an indication on which variables contribute most to explaining the regressant ${ }^{19}$.

Second, the size and sign of the coefficients of a 'best' model can be interpreted. We define the best model as the model that best performs an $\mathrm{n}-1$ prediction exercise. That is, we do not focus on maximising the goodness of fit, but want to minimise the forecasting error. This allows an indication which combination of factors is best able to predict patenting and whether these factors have a positive or negative impact on the prediction. The standard Lasso does not come with an easy way to calculate the standard errors of the coefficient estimates, and a Bayesian approach would help in this regard. In any case, it is interesting to see which variables are most effective in explaining the variation in the explained variable, and in which direction this variation appears.

In order to make the results more easily interpretable, all variables are standardised. Also, model selection is restricted to models with at most 25 explanatory variables.

We present the result for solar in Table 4. The Lasso algorithm only selects 11 out of the 47,000 variables as being most relevant for predicting solar patenting behaviour.

The first, observation is that rdd_solar and rdd_res, i.e, the spending on RD\&D for solar and the spending on RD\&D for all renewables have a measurable effect. The delay with which rdd_solar increases patenting appears to be three to four years.

A second observation in that pat_total is important. We interpret this variable as a control for the overall patenting activity in a country/year.

\footnotetext{
${ }^{19}$ For shrinkage estimators such as ridge or lasso ' $f($ betas $)<c$ ' for some function $f$ and some constant $c$. With the ridge, $f$ is the sum of the squares of the coefficients. Hence in the Ridge, all coefficients are non-zero, but a larger value is assigned to the coefficient that helps reducing the SSR the most. With the Lasso, $f$ is the sum of the absolute values of the coefficients. Thus again, we obtain larger beta for variables that help reducing SSR, but in addition, the least significant coefficients are forced to 0 .
} 
The third important variable is market size. If dep_total is large, the impact of rdd_solar on patenting gets bigger.

Table 4: Results for solar photovoltaic

\begin{tabular}{|l|l|}
\hline (Intercept] & 2.849 \\
\hline pat_total_rooted & 0.183 \\
\hline pat_total_rooted_lag2 & 0.071 \\
\hline pat_total_rooted_partsum1_lag1 & 0.003 \\
\hline pat_total_rooted_partsum2_lag1 & 0.022 \\
\hline rdd_solar_squared : dep_total_partsum3_lag3 & 0.050 \\
\hline dep_tech_lag3 : rdd_res_squared_lag5 & 0.022 \\
\hline rdd_res_squared_lag5 : dep_solar_partsum1_lag2 & 0.007 \\
\hline rdd_res_squared_lag5 : dep_solar_partsum2_lag2 & 0.036 \\
\hline rdd_res_rooted_lag5 : rdd_solar_rooted_lag4 & 0.336 \\
\hline rdd_res_rooted_lag5 : rdd_solar_rooted_partsum1_lag3 & 0.000 \\
\hline $\begin{array}{l}\text { Note: Model chosen from >47000 variables based on the lowest mean square error in predicting } \\
\text { the n'th observation based on n-1 data. Coefficients rounded at the third decimal digit. Number of } \\
\text { included variables limited to 25 during model selection. }\end{array}$ \\
\hline
\end{tabular}

The stability of the above-presented results is confirmed by a plot of the coefficients selected by the Lasso for a range of lambdas.

\section{Figure 8: Coefficients for solar patents at different lambda}

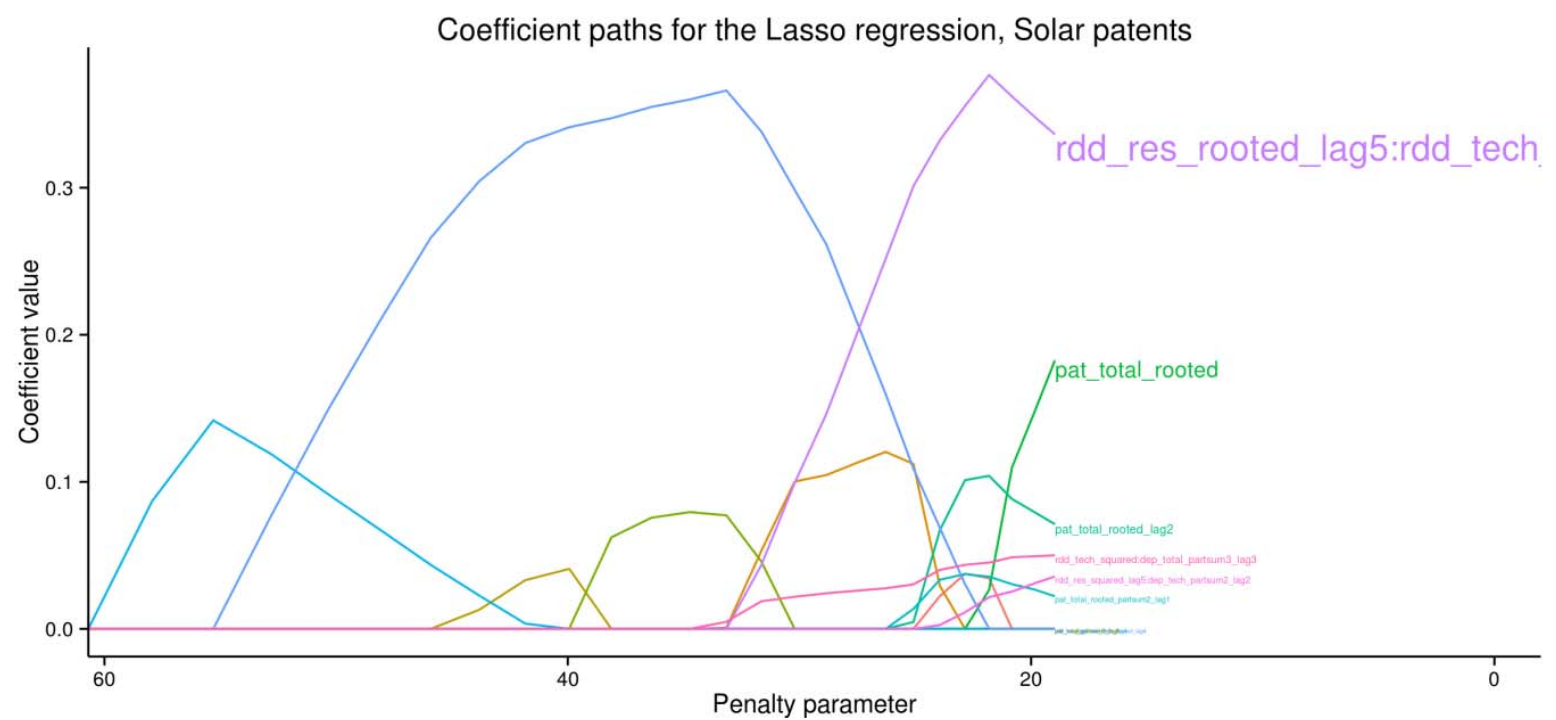

For wind, a larger number of variables have been included in the estimation by the Lasso.

Again, total patenting (pat_total) is controlling for the general propensity to patent in a given country in a given year. And patenting in solar (pat_solar) seems even better suited to control for the propensity to patent in (renewable?) energy technologies. 
Also, RD\&D spending on wind technology seems to encourage patenting in this area. We find rather long and disperse time-lags for the effect of RD\&D on patenting. RD\&D between the second to sixth year (partsum5 lag2) seems to be most effective.

The most interesting finding in our view is that the effect of RD\&D spending on wind technologies gets substantially augmented when the deployment of wind turbines on the continent is high (continent_dep_wind : rdd_wind). Again timing matters, current deployment based on past RD\&D spending coincides best with patenting.

Beyond these three main drivers, there are a number of variables with typically small negative values that are somewhat difficult to interpret. We would see them as correction factors that reduce the aforementioned effects in certain conditions. The largest is the interaction of RD\&D spending on renewables with the deployment of wind on the continent (continent_dep_wind : rdd_res]. One way of interpreting this is that countries with a lot of nonwind RD\&D spending do not benefit (in terms of wind patents] as much from the deployment of wind turbines on their continent, as countries that focus their renewables RD\&D on wind.

\section{Table 5: Results for wind power}

\begin{tabular}{|c|c|}
\hline Intercept & 2.014 \\
\hline continent dep_wind lag 5 : rdd res_squared_partsum 3 lag2 & -0.055 \\
\hline continent dep_wind partsum4 lag 3 : rdd res_squared partsum 1 lag 3 & -0.012 \\
\hline continent dep_wind partsum 4 lag 3 : rdd res squared partsum 2 lag2 & -0.068 \\
\hline continent dep_wind partsum4 lag 3 : rdd res_squared_partsum 2 lag 3 & -0.062 \\
\hline continent dep_wind partsum 5 lag 2 : rdd res squared partsum 2 lag2 & 0 \\
\hline continent dep_wind : rdd_wind partsum5 lag3 & 0.009 \\
\hline continent dep_wind : rdd wind rooted & 0.062 \\
\hline continent dep_wind : rdd_wind rooted lag2 & 0.188 \\
\hline continent dep_wind : rdd_wind rooted_partsum 1 lag1 & 0.012 \\
\hline continent dep_wind : rdd_wind rooted partsum 5 lag 3 & 0.199 \\
\hline dep_total lag5 : continent dep_wind partsum2 lag1 & -0.003 \\
\hline dep total : rdd wind partsum2 & -0.008 \\
\hline dep_wind dwdist : rdd_wind dwdist & -0.016 \\
\hline dep_wind : dep_wind_dwdistwces & 0.069 \\
\hline pat solar rooted lag1 & 0.36 \\
\hline pat_solar_rooted_partsum 1 & 0.034 \\
\hline pat total logged & 0.068 \\
\hline rdd_res_squared_lag4 : continent_dep_wind_partsum4_lag3 & -0.045 \\
\hline rdd_wind rooted lag5 & 0.015 \\
\hline rdd_wind rooted partsum 3 lag2 & 0.002 \\
\hline rdd_wind rooted partsum 5 lag2 & 0.346 \\
\hline $\begin{array}{l}\text { Note: Model chosen from }>47000 \text { variables based on the lowest mean square error in predicting } \\
\text { the n'th observation based on } n-1 \text { data. Coefficients rounded at the third decimal digit. }\end{array}$ & \\
\hline
\end{tabular}

The stability of the above-presented results is confirmed by a plot of the coefficients selected by the Lasso for a range of lambdas. 


\section{Figure 8: Coefficients for wind patents at different lambda}

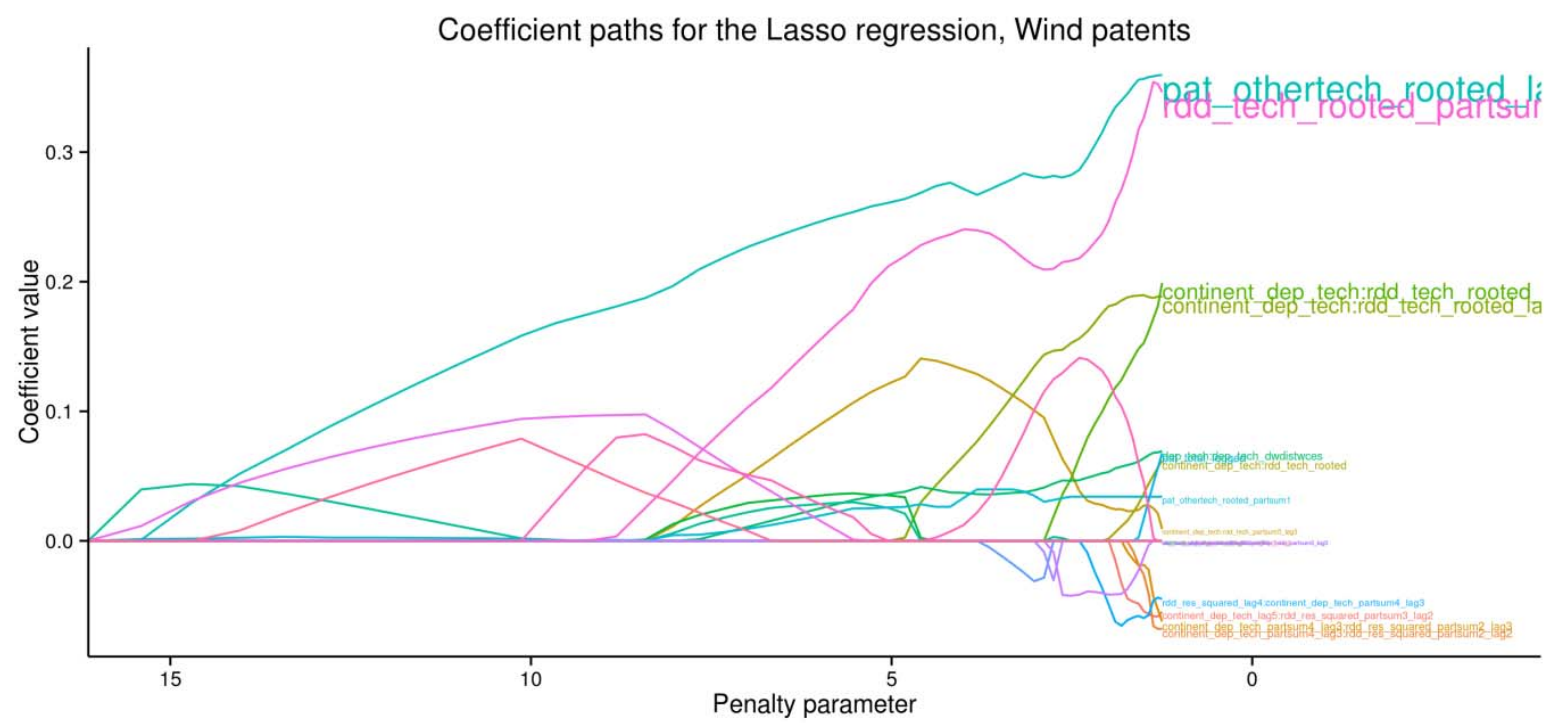

To get some indication of the quality of our results we calculate the share of variance in the patenting behaviour our model is able to explain (similar to the $\mathrm{R}^{2}$ ). The results are displayed in the following table. Given their parsimonious parameterisation the 'goodness-of-fit' performance of both models is impressive.

Table 6: Deviance ratio for models explaining patenting behaviour in wind and solar

\begin{tabular}{|l|l|l|}
\hline & Deviance ratio & N of variables incl. intercept \\
\hline Solar patents & 0.73 & 11 \\
\hline Wind patents & 0.75 & 22 \\
\hline
\end{tabular}

To visualise the size and timing of the effect we display the response to a hypothetical shock predicted by the presented model parameterisation.

\section{Effect of a joint policy}

As indicated by the coefficient estimates, increasing both RD\&D spending and deployment results in a substantial effect on patenting in the respective technologies. The effect on wind and solar implies that annual patenting might about double when the assumed policies are carried out. 
Figure 9: Predicted response to an increase in RD\&D spending and deployment in Germany by one standard deviation on patenting in solar [left] and wind [right] in Germany

\section{Increase RD\&D and deployment in Germany}
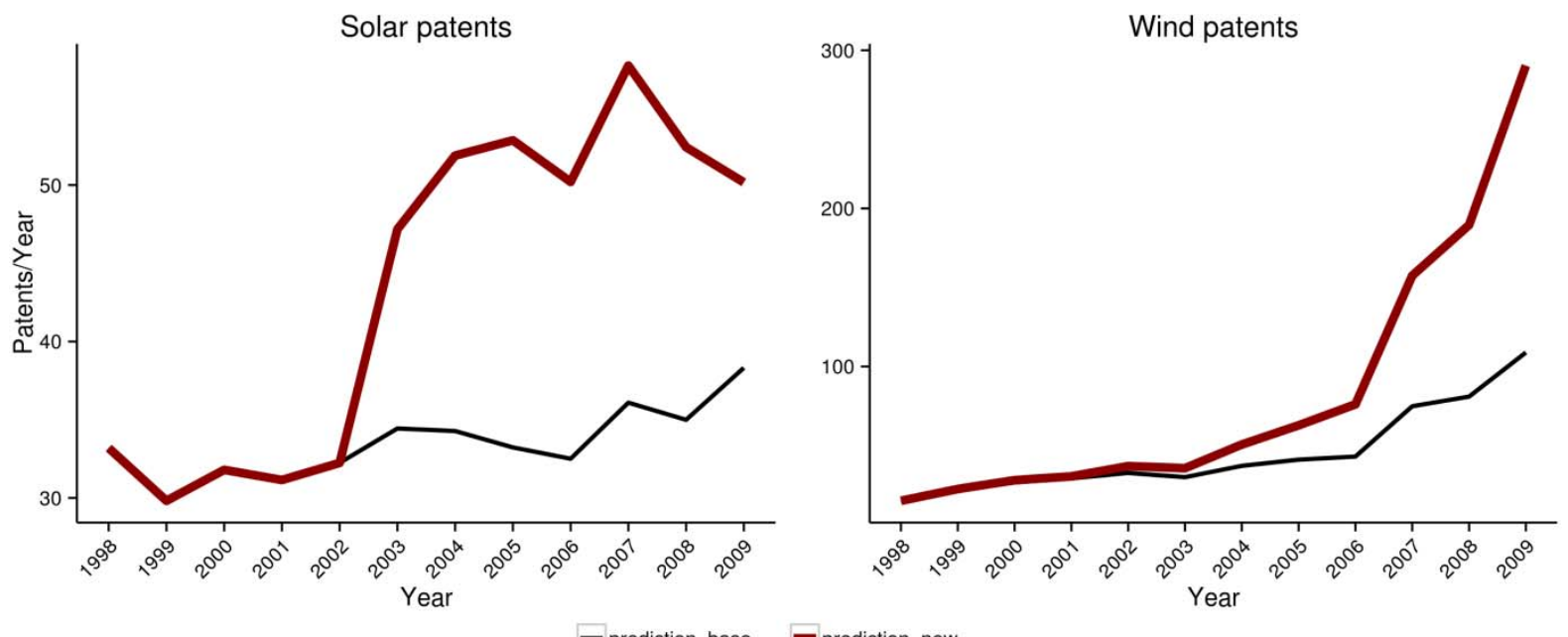

— prediction_base

- prediction_new

\section{Effect of only RD\&D support}

Increasing RD\&D support by one standard deviation over a period of time has a substantial impact on patenting in this technology.

Figure 10: Predicted response to an increase in RD\&D spending in Germany by one standard deviation on patenting in solar (left) and wind (right) in Germany

Increase RD\&D in Germany
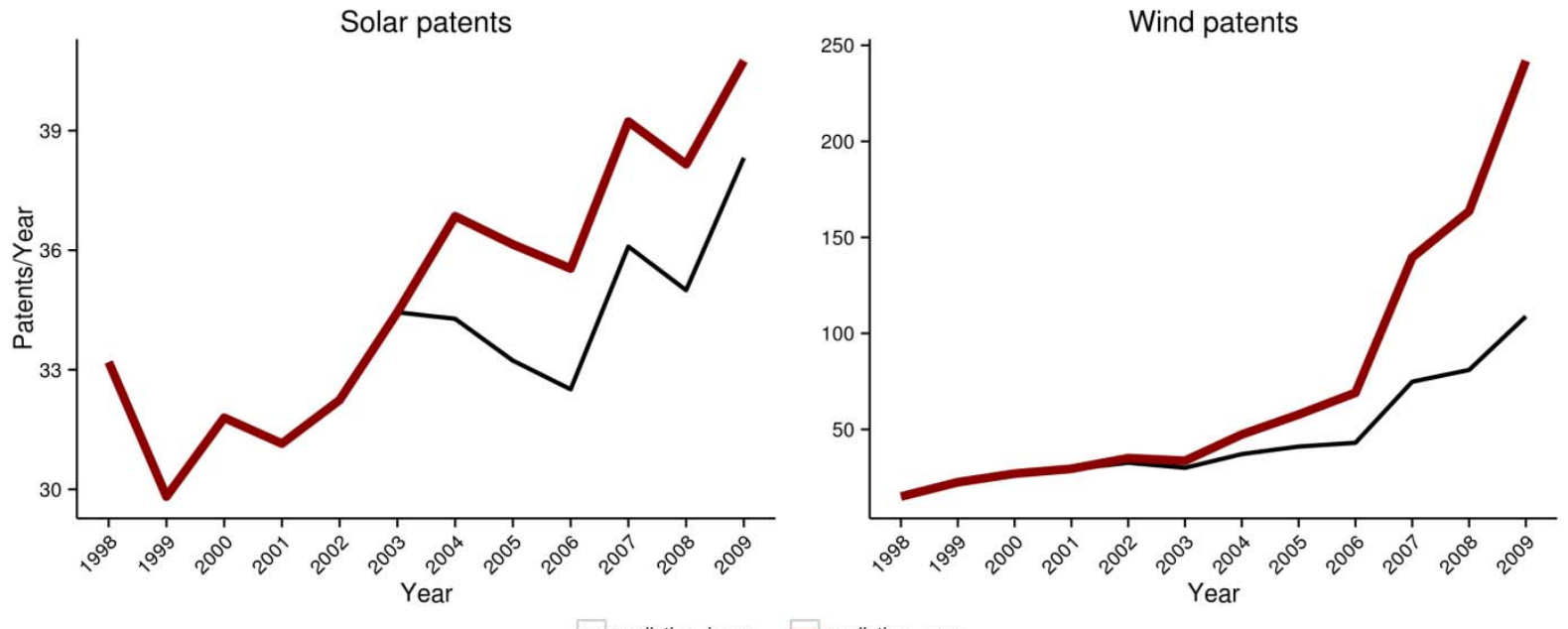

- prediction_base

- prediction_new 
Solar deployment has a strong effect on solar patenting. On the other hand, the effect of wind- deployment on patenting is modest.

Figure 11: Predicted response to an increase in deployment in Germany by one standard deviation on patenting in solar [left] and wind [right] in Germany

Increase deployment in Germany
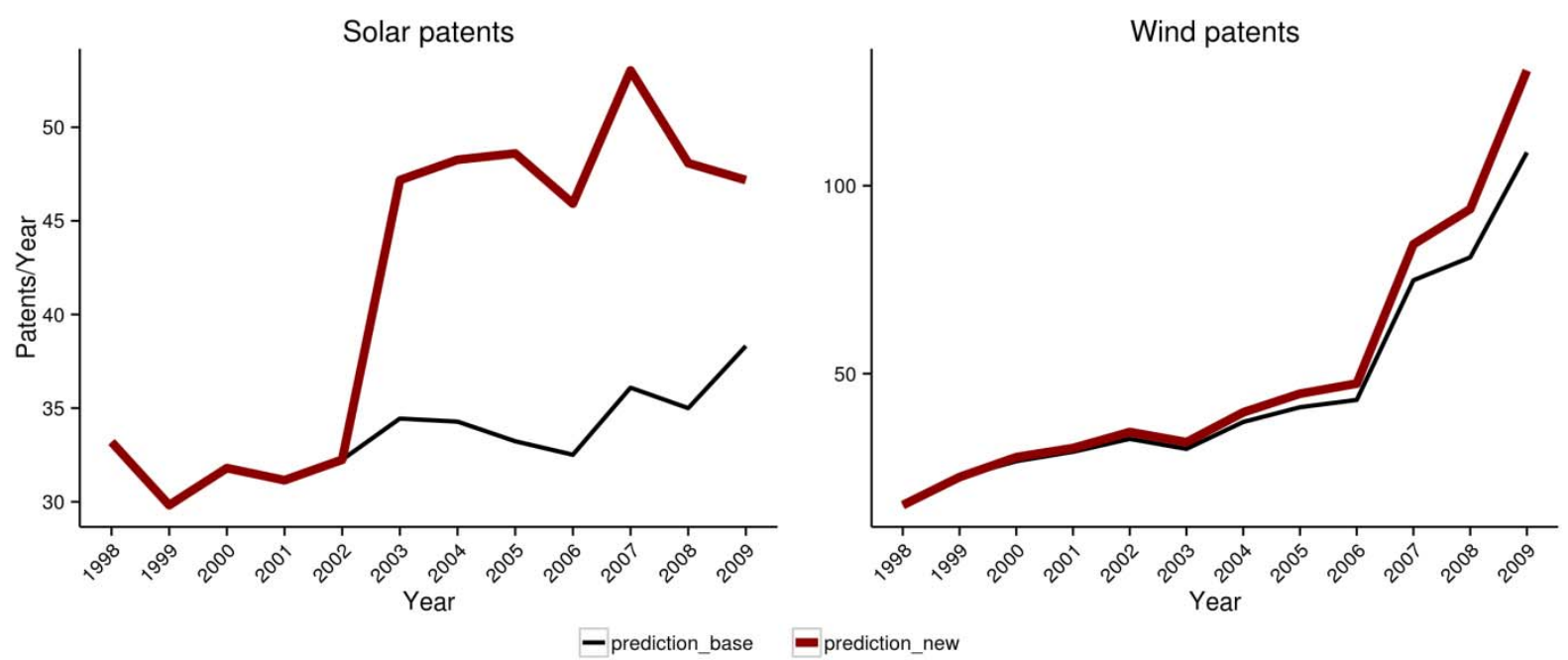

- prediction_base $\quad$ prediction_new

\section{Effect of policy combination}

We find above, that both deployment and RD\&D spending individually drive patenting and that consequently the policy combination is also having a positive effect. Figure 12 illustrates that the combination of both policies is, as was indicated by the positive interaction terms, more than the sum of its parts. In fact, for wind the additional benefit in terms of patents when joining policies is up to 25 percent (for solar 1 percent). 
Figure 12: Predicted difference between a combined increase in deployment and RD\&D on patenting in solar [left] and wind [right] in Germany to the sum of the individual effects

\section{Policy combination}

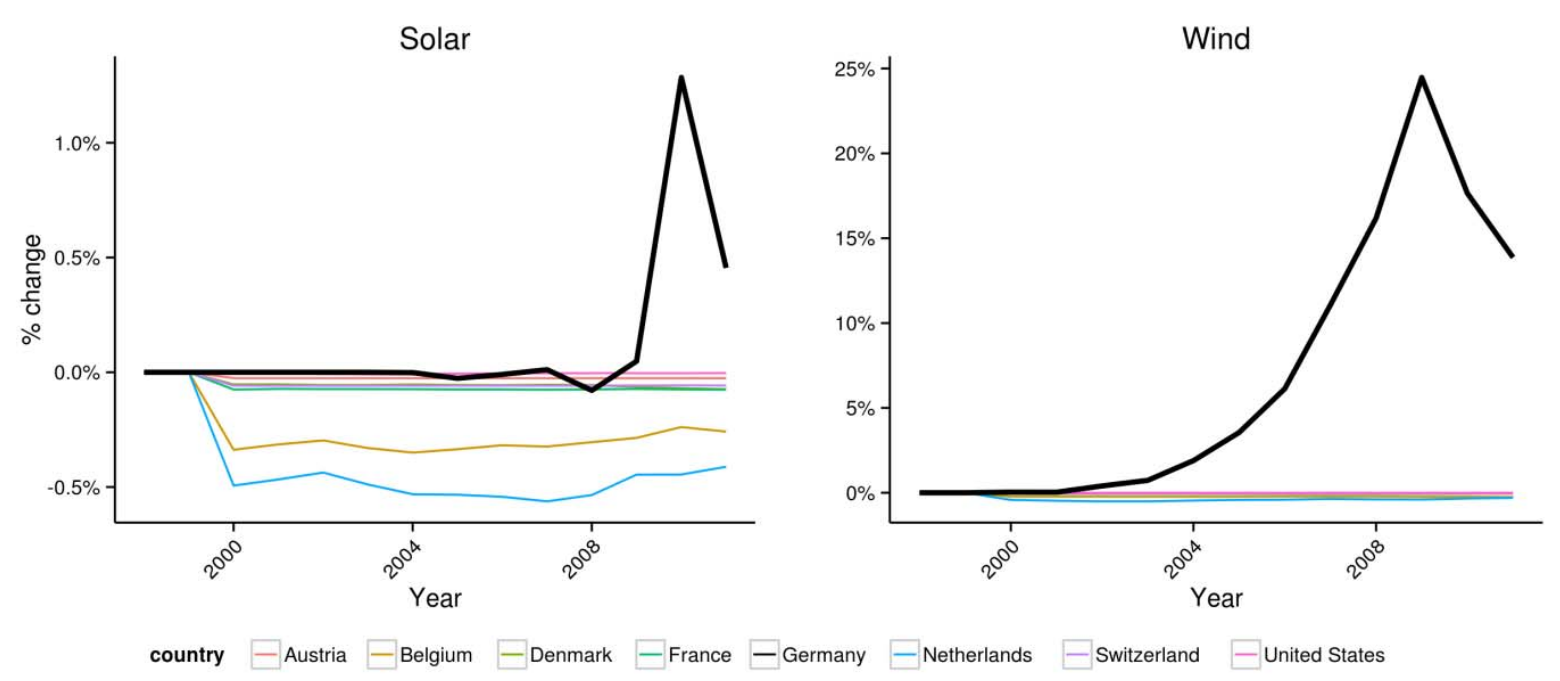

\section{Cross-border spillover}

The coefficients indicated an effect of deployment and RD\&D spending in one country on patenting in neighbouring countries. Figure 13 confirms that this effect is significant for the impact of wind deployment 
Figure 13: Predicted response to an increase in RD\&D (above) and deployment (below) by one standard deviation on patenting in solar (left) and wind (right) in Germany

Cross-border effects
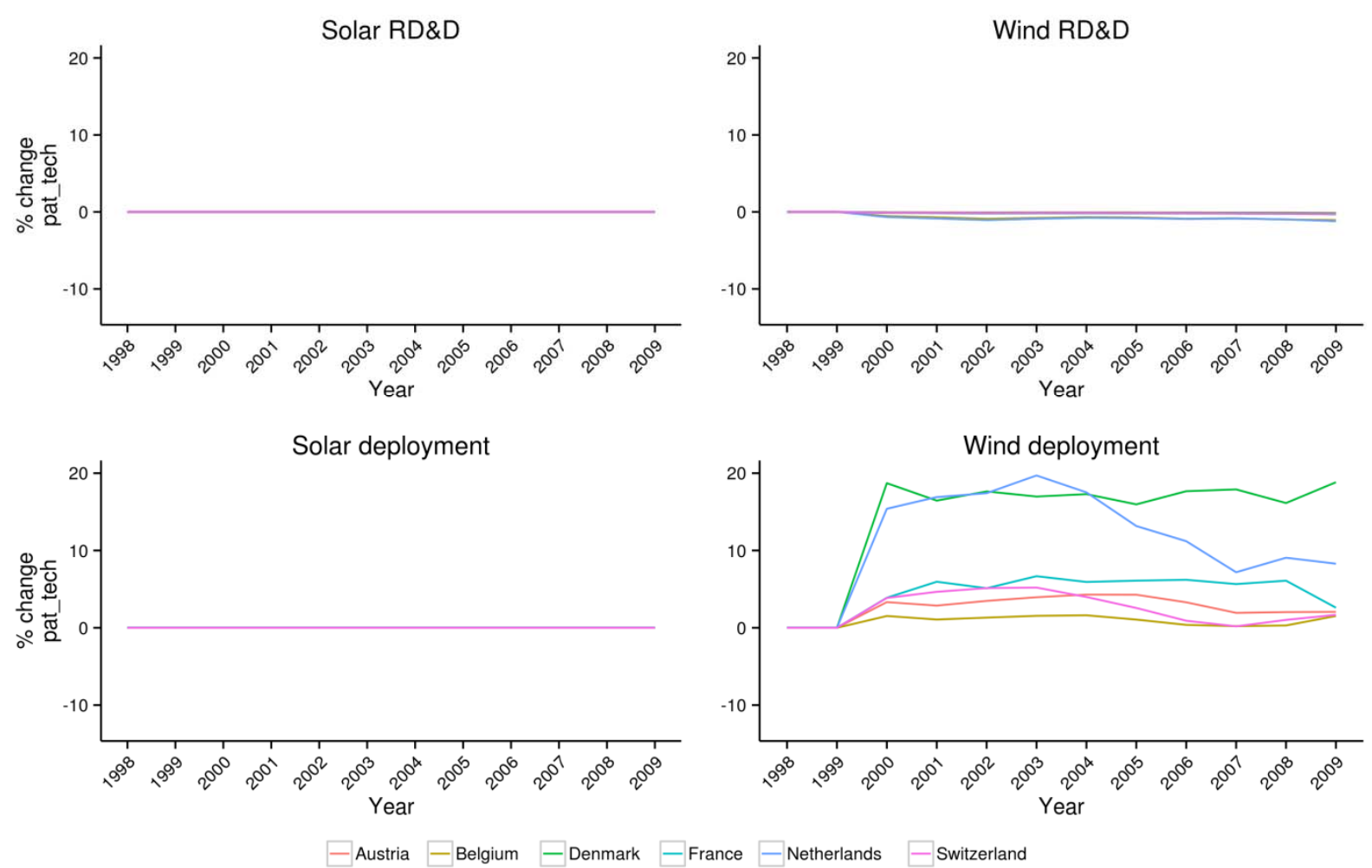

\section{From patents to competitiveness}

The explained variable, number of patents in the narrowly define technology, is only an imperfect proxy for what policy would really care about - innovation leading to sustainable reduction in the total cost of using the technology to replace existing technologies ${ }^{20}$. To also capture cost-savings that improve the technology beyond patented innovation we repeat the analysis using the inverse RCA ranking. This should allow us to understand which policies (deployment, RD\&D support or both) coincide with improvements in the competitiveness of the domestic renewable energy technology industry.

Overall, the results for RCA are significantly less robust. Obviously, the comparative advantage and its development over time is determined by many factors do not properly control for (labour cost, education, capital cost, etc.). Consequently, the variation of RCA explained by a relatively sparse model of less than 25 variables is low if compared to the results obtained in the patents regression. Thus, the results below should be interpreted

\footnotetext{
${ }^{20}$ Popp et al (2011) for example argue that the diffusion of renewables is mainly driven by regulation and less by the knowledge stock.
} 
with a substantial degree of caution ${ }^{21}$. The major factor that helps predicting the revealed comparative advantage in wind and solar in a country, is the logged number of all patents granted in this country in this year (pat total logged, see Tables in the Annex). This indicates that a key driver of export specialisation in renewables is the innovative power of a country.

Table 7: Deviance ratio for models explaining the RCA in wind and solar

\begin{tabular}{|l|l|l|}
\hline (sparse model) & Deviance ratio & N of variables incl. intercept \\
\hline Solar RCA ranking & 0.29 & 23 \\
\hline Wind RCA ranking & 0.46 & 23 \\
\hline
\end{tabular}

\section{Deployment and competitiveness}

The clearest result for competitiveness is that deployment is indeed increasing the competitiveness of the corresponding technology. A sustained increase in domestic deployment of wind turbines increases the RCA ranking in wind turbines by about one position in the case of Germany. For solar panels there is also a clearly positive impact. Countries which deploy more solar panels are also exporting more of them in future. The clarity of the results somewhat surprised us, as our prior was that larger deployment coincides with larger domestic demand and hence more limited room for exports.

Figure 14: Predicted response to an increase in deployment by one standard deviation on the RCA in solar [left] and wind [right] in Germany

Increase deployment in Germany

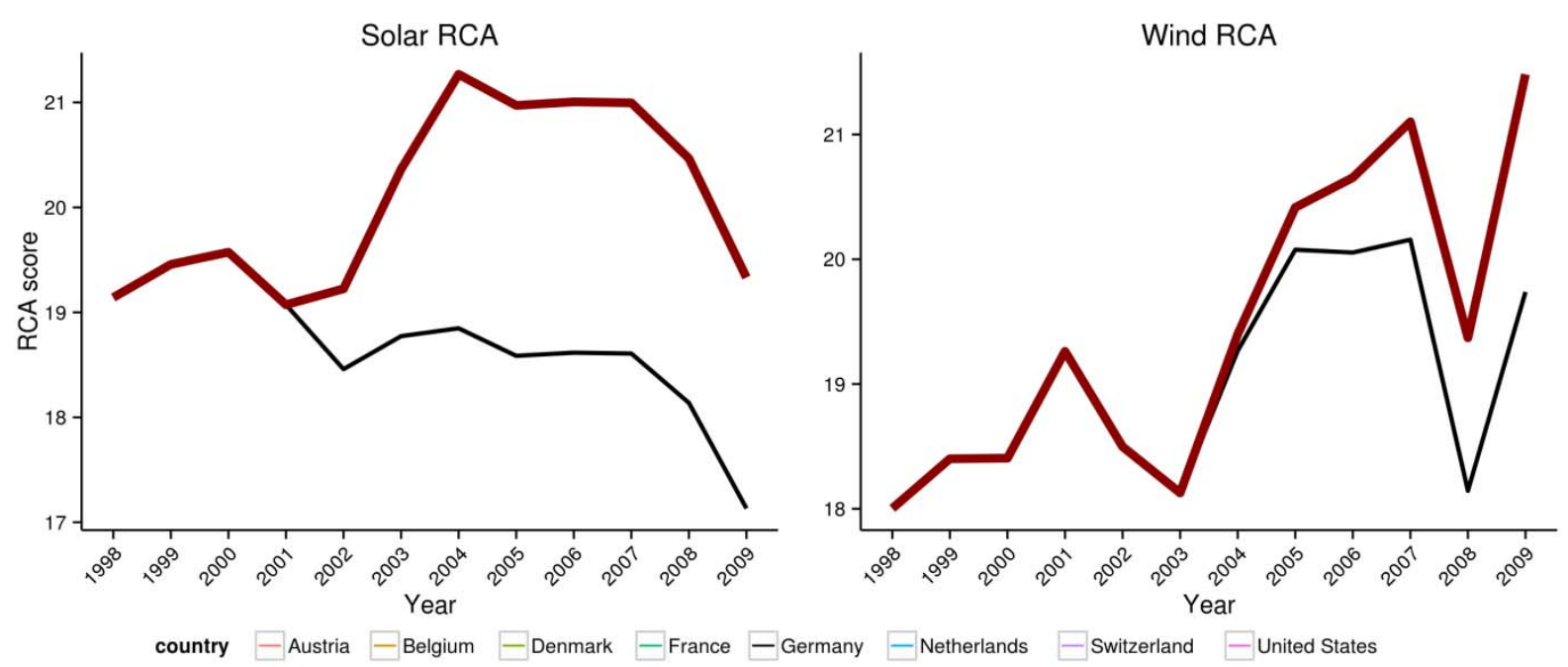

\footnotetext{
${ }^{21}$ We force the model selection to the subset of models that include 25 explanatory variables or less, as we noticed a tendency towards models with more than one hundred explanatory variables when only optimising on the in-sample predictive power.
} 


\section{RD\&D and competitiveness}

The results for the impact of RD\&D on competitiveness seem all not very meaningful. Our prior would be to find a positive impact of domestic support on RD\&D support on the competitive position of the corresponding technology. By contrast, our results indicate that the impact of RD\&D is insignificant.

Figure 15: Predicted response to an increase in RD\&D expenditure by one standard deviation on the RCA in solar [left] and wind [right] in Germany

Increase RD\&D in Germany
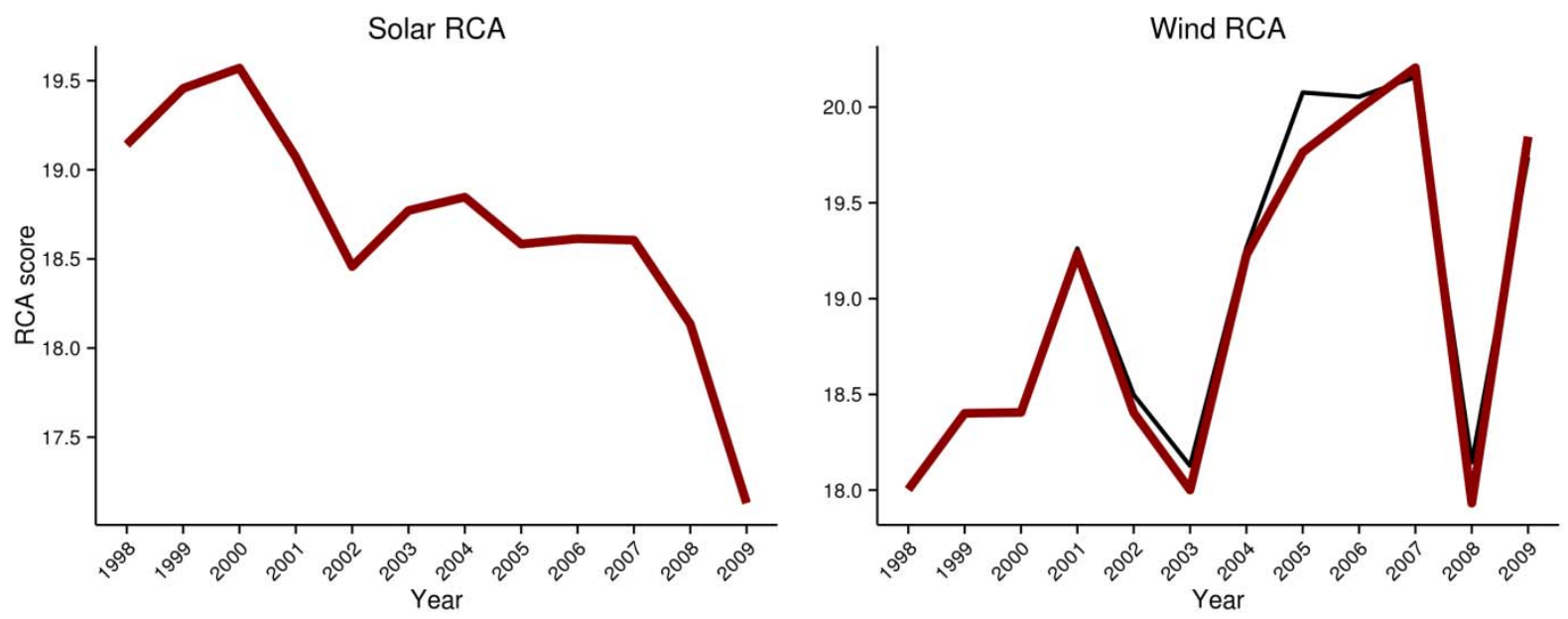

Policy combination and competitiveness

This picture is confirmed for policy combination. For wind turbines having both policies in place at the same time increase the competitive position more than the effect of the individual policies together. For solar panels, we find a very small, negative impact of policy combination. 
Figure 16: Predicted difference between a combined increase in deployment and RD\&D on the RCA in solar [left] and wind [right] in Germany to the sum of the individual effects

Policy combination

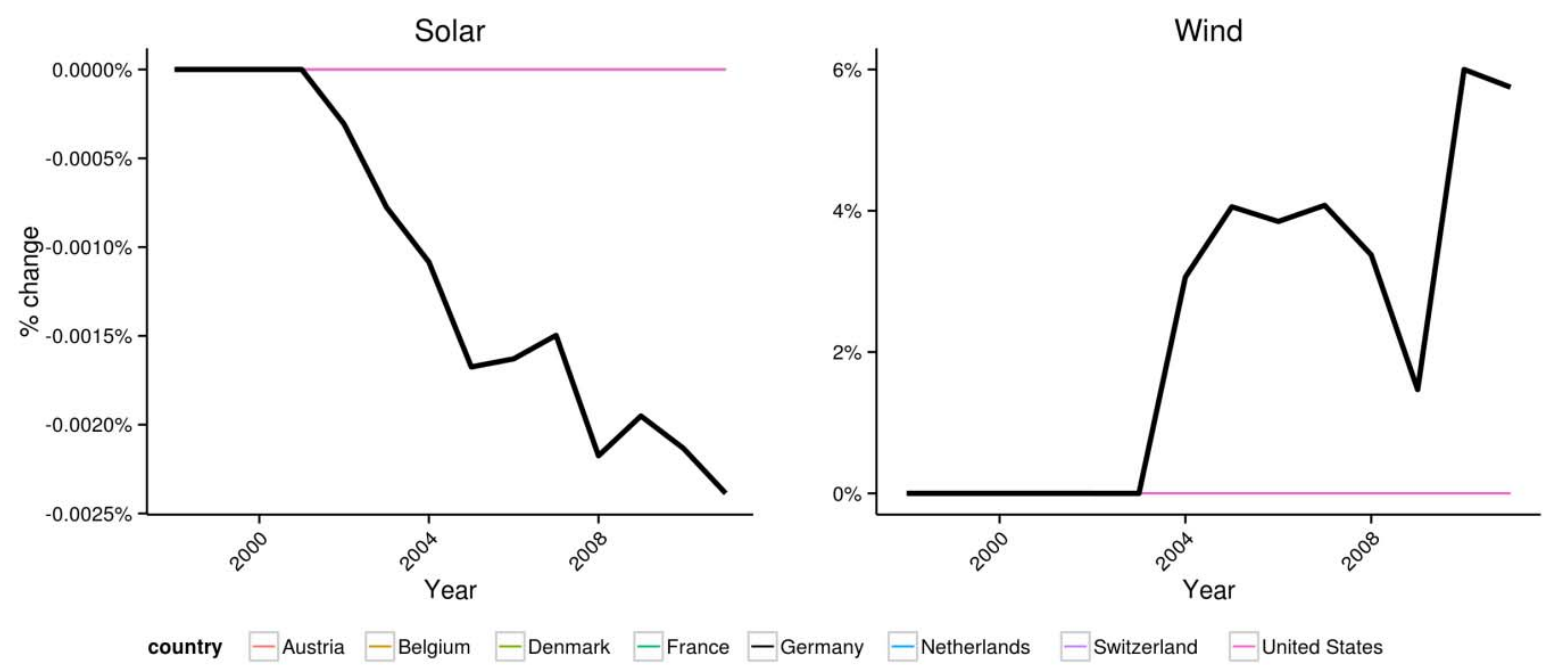

\section{Discussion}

Our results suffer from a number of potential drawbacks:

- Additional explanatory variables and controls for locational factors (sun, wind conditions], neighbouring country effects, interaction terms, non-linear relationships and others could make sense.

- Our econometric approach does not allow us to fully explore the potentially complex interactions between the analysed variables. Whether a certain factor such as 'deployment in the past five years' is a true cause, or just an intermediate variable itself being caused by past knowledge stock and RD\&D activities cannot be properly disentangled. In the same vein we cannot separate cause-and-effect for explained and explanatory variables. Such endogeneity might for example arise because countries that were successful in renewable innovation in the past might feel encouraged to invest more in this field. Hence, our results do not allow us to properly assess the impact of additional RD\&D spending in $t$ on patenting in all subsequent periods, as this would require a (theoretically founded) structural model of all interactions.

- Furthermore, our model might just be an 'explanation in hindsight', meaning that it might explain those 13 years for the 28 countries but not earlier years or future years or other countries.

- The explained variable, number of patents in the narrowly defined technology, is only an imperfect proxy for what policy would really care about - innovation leading to sustainable reduction in the total cost of using the technology to replace existing technologies ${ }^{22}$. That is, we neither cover how patenting

\footnotetext{
${ }^{22}$ Popp et al (2011) for example argue that the diffusion of renewables is mainly driven by regulation and less by the knowledge stock.
} 
in complementary technologies such as storage is affected, nor can we measure unpatented innovation (such as process innovation or scale effects) that might have substantial cost-saving effects. We also do not know the actual cost-reduction effect of the patents. On the other hand, the relative competitiveness of exports on the global market - as measured by the RCA ranking - seems not to be a good proxy either.

- Furthermore, we cannot give meaningful p-values, so some of the coefficients might have just been included by chance. Going for a Bayesian approach might allow an assessment of the confidence we put into the individual parameter estimates. In addition, it would allow us to include prior information (such as interactions deduced from theory). Hence, a corresponding implementation is very promising but had to be left to further research.

Our results can at most shed light on what timing and balance of national support policies coincided with a certain patenting behaviour. This finding cannot, however, be directly translated into which policy combination is efficient. Such a 'policy optimisation' would require the parameterisation of the 'patent production function' to be complemented by a cost-function of the policies. Based on this, an 'optimal' policy balance and timing could be determined. Obviously, the parameterisation of the model would need to be constantly updated because the persistence of the interaction is not given. In fact, it would be akin to optimising a portfolio of policies in order to produce the maximum number of patents or maximise the competitiveness ranking. Similarly to financial hedging strategies, such a 'portfolio optimisation' approach would not work in the case of an event that was not observed in the historical data used for parameterisation ['black swan']. Consequently, the choice of deployment and RD\&D support policy should not be mechanically based on a quantitative optimisation strategy. Nevertheless quantitative 'policy optimisation' could serve as valuable additional tool in particular as a benchmark against existing ['shot-in-the-dark'] strategies.

\section{Conclusion}

Our results are in line with the hypothesis that deployment and RD\&D expenditure both have an impact on technology development. Our finding that the combination of deployment and RD\&D expenditures has a positive impact on patenting is in line with two-factor learning curves.

Our results indicate substantial differences in the 'patent production function' between the two analysed technologies. While solar patenting strongly coincides with both past RD\&D expenditures and deployment, wind patenting did not coincide with deployment alone, but was strongest in countries that featured a policy combination of RD\&D expenditures and deployment. Whether this points to idiosyncratic learning curves for each technology, or whether certain technology families enjoy more similar learning curves or if technologies at a similar stage of maturity enjoy similar learning curves, is left for further research. 
In addition, our results indicate that timing, cross-border spillovers and technology spillovers matter for the success of support policies. With respect to timing, the data suggests that a certain sequence of RD\&D support and deployment is most strongly linked to patenting. In particular we find that deployment based on earlier RD\&D expenditures strongly coincides with wind innovation. Cross-border spillovers play a positive role for wind deployment. Finally, we have (slight) evidence that technology spillovers might matter for patenting.

\section{Policy implications}

Our findings are in line with the hypothesis that both deployment and RD\&D support are effective in advancing technology development. Our results also imply that the weight and timing of deployment and RD\&D support matter. That is, certain combinations of deployment and RD\&D support are more efficient than others. This calls for a strategic approach towards renewable energy technology support. Furthermore, the existence of substantial cross-border spillovers from deployment implies that international coordination might make renewable energy technology support more efficient.

Consequently, going beyond an uncoordinated 'shot-in-the-dark' is worthwhile, though more research is necessary to identify support structures that are resilient and efficient. In this respect, given the size of the issue (recall: about $€ 48$ billion spent on deployment and $€ 315$ million spent on RD\&D support in the five largest EU countries in 2012) investing more in ex-ante and ex-post evaluation of renewable energy technology support schemes is a 'no regret option'. 


\section{References}

Arrow, K. (1962) 'Economic welfare and the allocation of resources for invention', in R.R. Nelson (ed.) The Rate and Direction of Inventive Activity, pp 609-625, Princeton University Press, Princeton, NJ

Bettencourt, L.M.A., Trancik, J.E., and Kaur, J. (2013) 'Determinants of the Pace of Global Innovation in Energy Technologies', PLOS ONE, vol 8, no 10

Braun, F.G., Schmidt-Ehmcke, J., and Zloczysti, P. (2010) 'Innovative Activity in Wind and Solar Technology: Empirical Evidence on Knowledge Spillovers Using Patent Data', CEPR Discussion Papers, no 7865

Gurmu, S., and Pérez-Sebastián, F. (2008) 'Patents, R\&D and lag effects: evidence from flexible methods for count panel data on manufacturing firms', Empirical Economics, vol. 35, no 3, pp 507-526

Jamasb, T., and Köhler, J. (2007) 'Learning curves for energy technology: a critical assessment', in M. Grubb, T. Jamasab, and M.G. Pollitt (eds) Delivering a Low Carbon Electricity System: Technologies, Economics and Policy, Cambridge University Press, Cambridge

Johnstone, N., Hascic, I., and Popp, D. (2010) 'Renewable Energy Policies and Technological Innovation: Evidence Based on Patent Counts', Environmental and Resource Economics, European Association of Environmental and Resource Economists, vol 45, no 1, pp 133-155

Junginger, M., Faaij, A. and Turkenburg, W.C. (2005) 'Global experience curves for wind farms', Energy Policy, vol 33, no 2, pp 133-150

Koseoglu, N.M., van den Bergh, J.C.J.M., and Subtil Lacerda, J. 'Allocating subsidies to R\&D or to market applications of renewable energy? Balance and geographical relevance', Energy for Sustainable Development, vol 17, no 5, pp 536-545

Popp, D. (2002) 'Induced Innovation and Energy Prices', American Economic Review, American Economic Association, vol 92, no 1, pp 160-180

Popp, D., Hascic, I., and Medhi, N. (2011) 'Technology and the diffusion of renewable energy', Energy Economics, vol 33, no 4, pp 648-662

Riess, A.D., Zachmann, G., Calthrop, E., and Kolev, A. (2012) 'Investment and growth in the time of climate change', Bruege/ Books

Sarasa-Maestro, C.J., Dufo-López, R., and Bernal-Agustín, J.L. (2013) 'Photovoltaic remuneration policies in the European Union', Energy Policy, vol 55, pp 317-328

Söderholm, P., and Sundqvist, T. (2007) 'Empirical challenges in the use of learning curves for assessing the economic prospects of renewable energy technologies', Renewable Energy, vol 32, no 15, pp 2559-2578

Tibshirani, R. (1996) 'Regression shrinkage and selection via the lasso', Journal of the Royal Statistical Society. Series B (Methodological), vol 58, no 1, pp 267-288

Van Benthem, A., Gillingham, K., and Sweeney, J. (2008) 'Learning-by-doing and the optimal solar policy in California', The Energy Journal, vol 29, no 3, pp 131-151

Wiesenthal, T., Dowling, P., Morbee, J., Thiel, C., Schade, B., Russ, P., Simoes, S., Peteves, S., Schoots, K., and Londo, M. (2012) 'Technology Learning Curves for Energy Policy Support', JRC Scientific and Policy Reports 


\section{Annex}

Patents regression

One-time shock

solar RD\&D

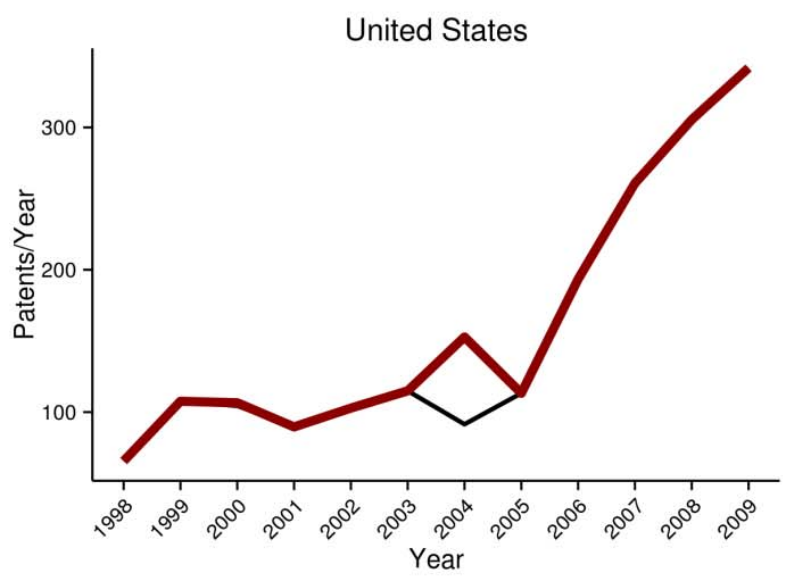

Germany

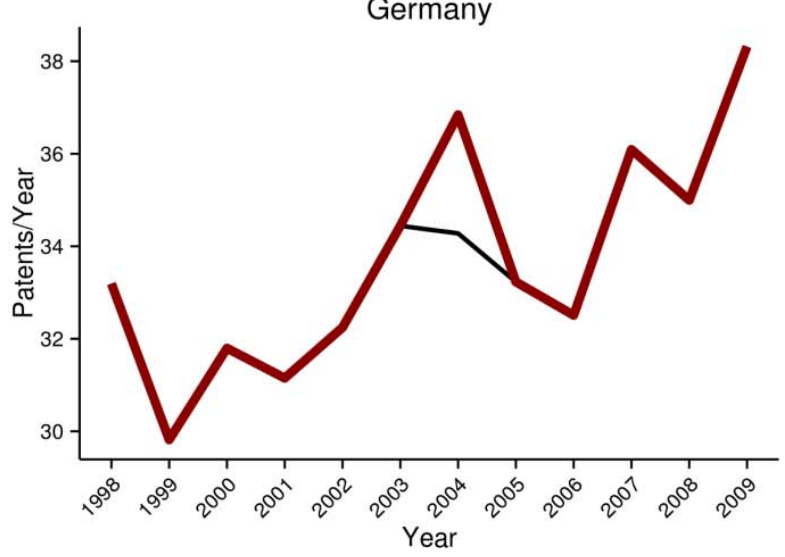

- prediction_base

Cross-border diffusion

from Germany

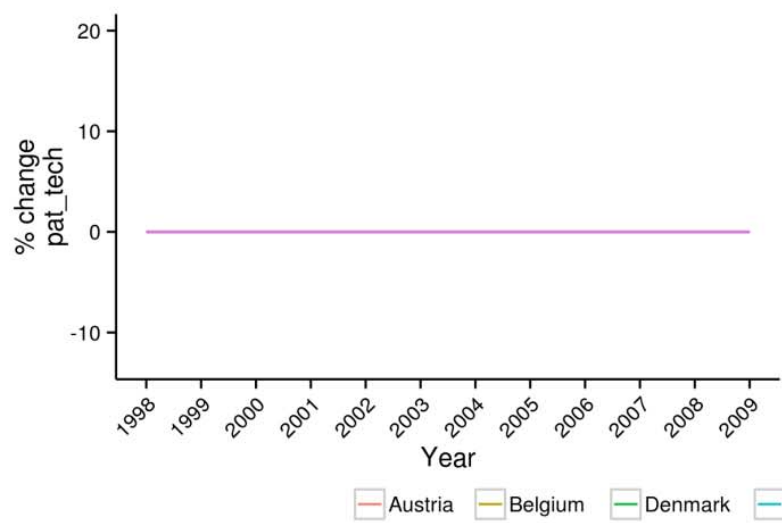

Repeated shock

solar RD\&D

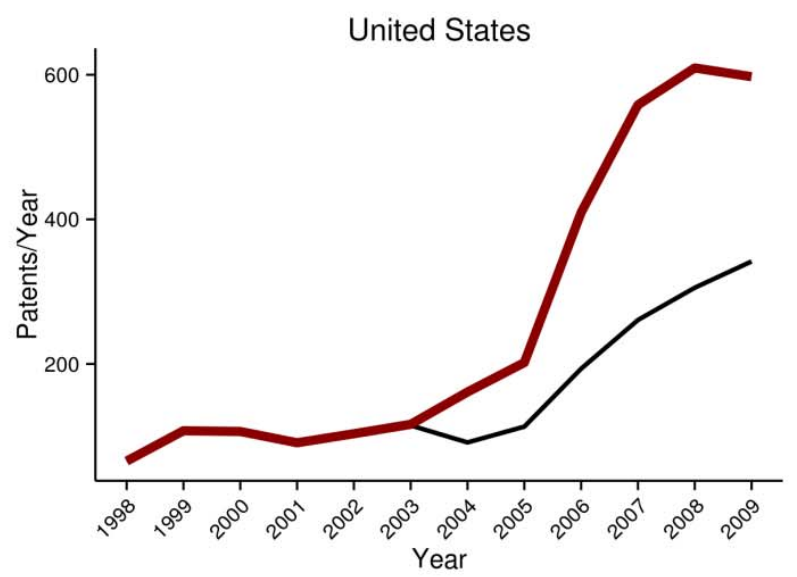

Germany

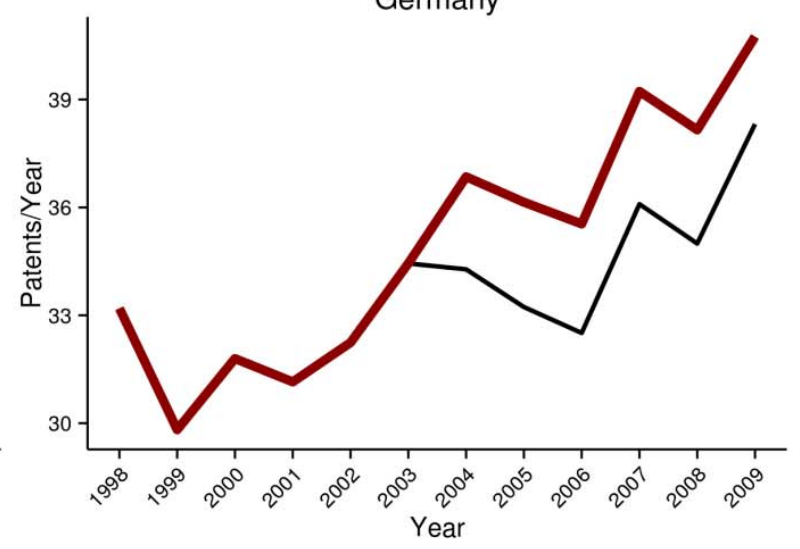

- prediction_new

Cross-border diffusion

from Germany

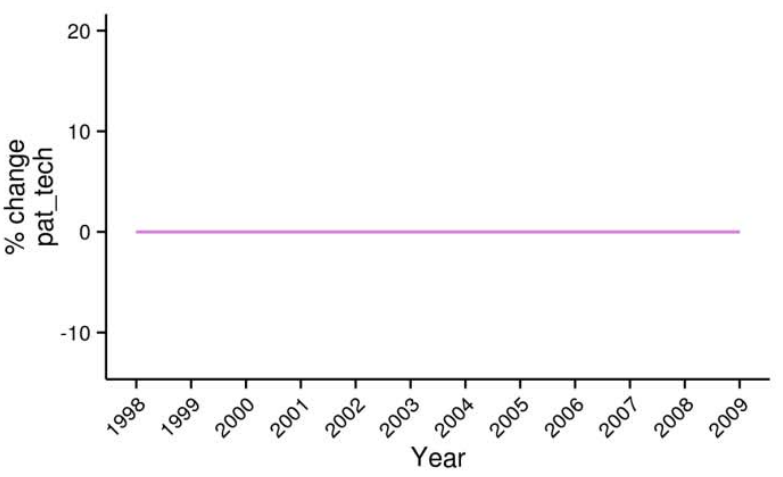


One-time shock

solar deployment
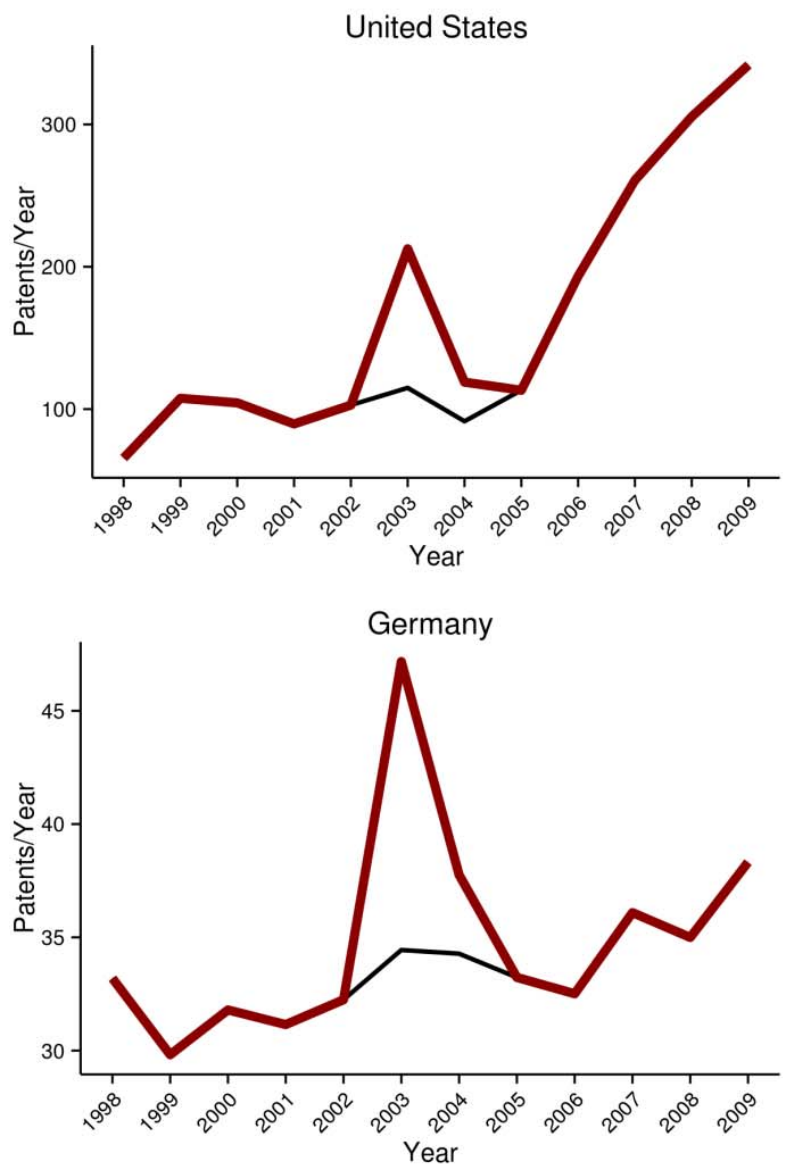

- prediction_base

Cross-border diffusion

from Germany

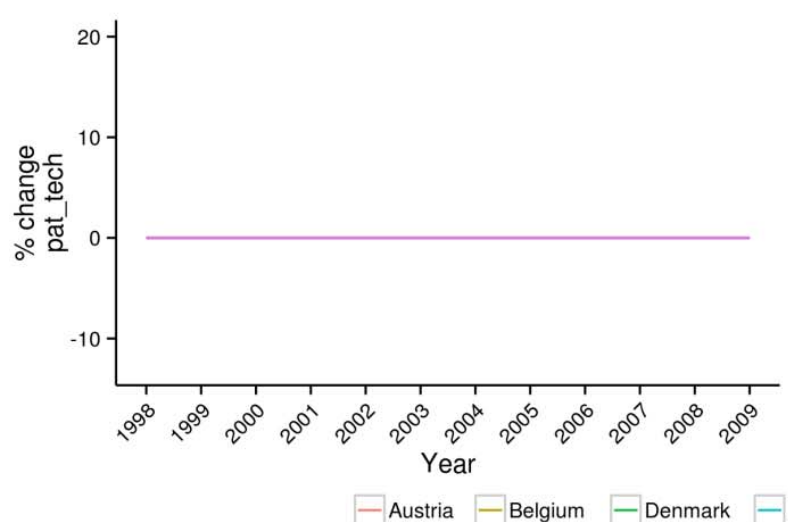

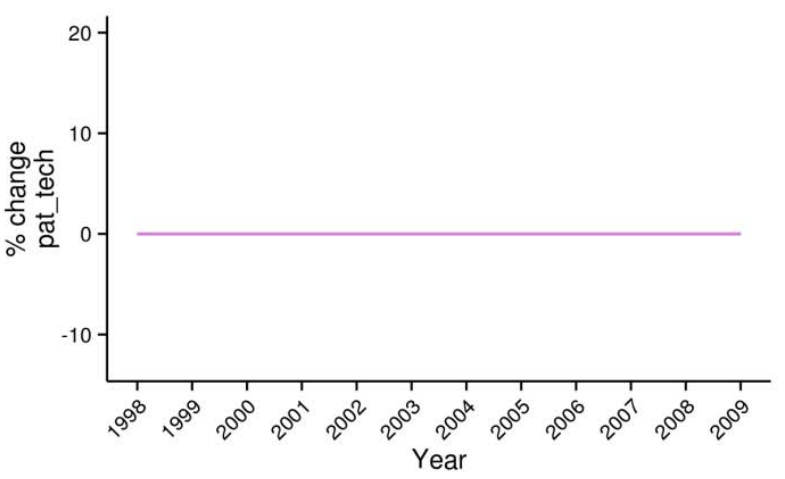

Repeated shock

solar deployment
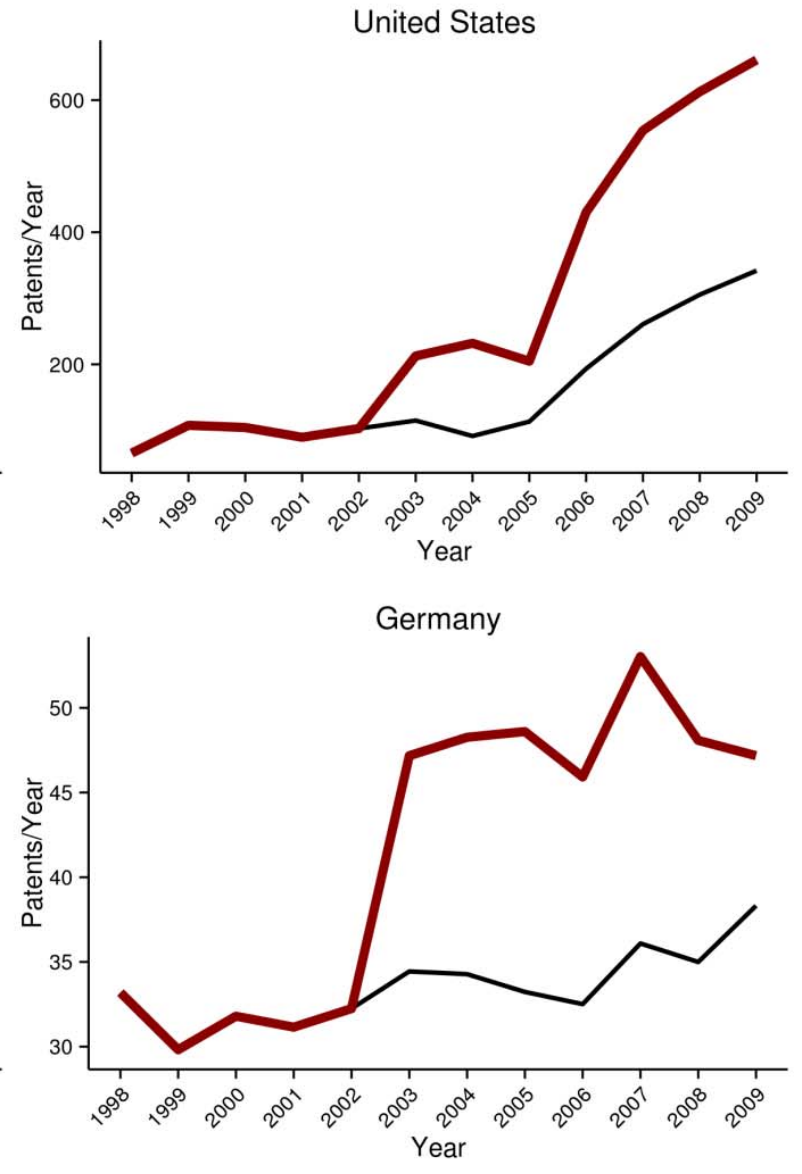

- prediction_new

Cross-border diffusion

from Germany

France $\square$ Netherlands $\square$ switzerland 
One-time shock solar RD\&D and deployment
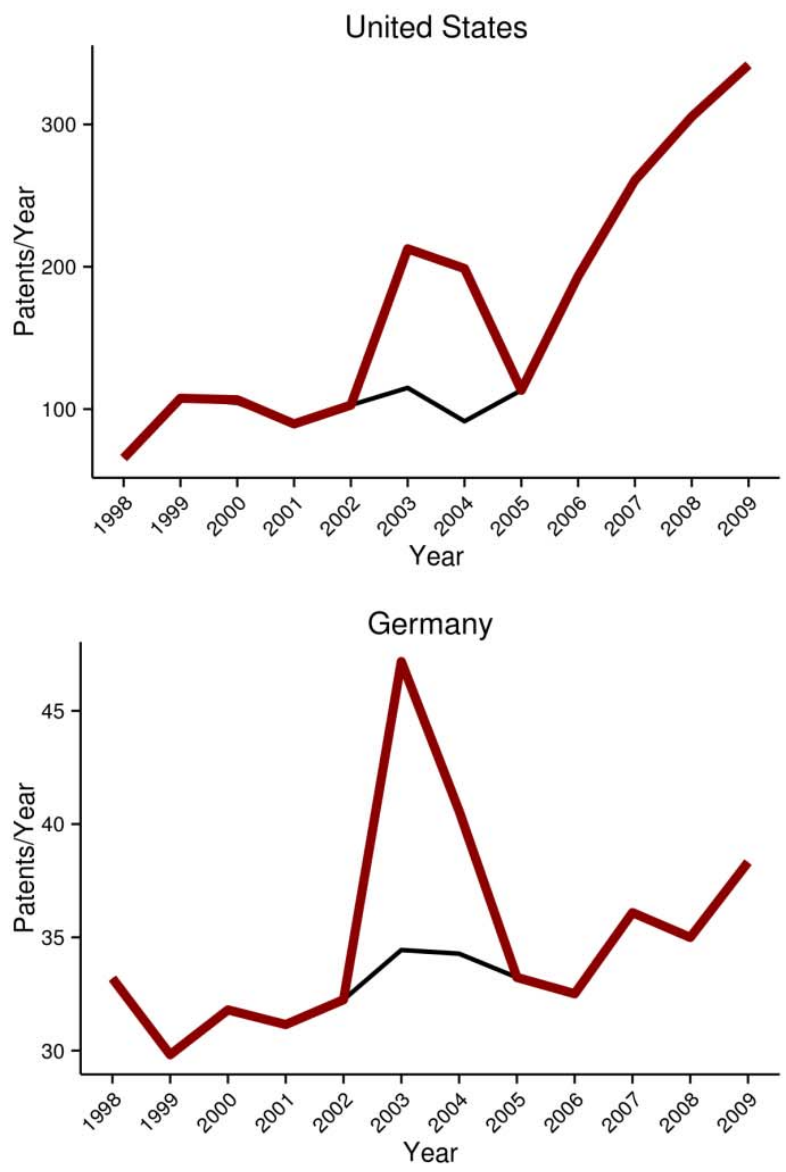

- prediction_base

Cross-border diffusion

from Germany

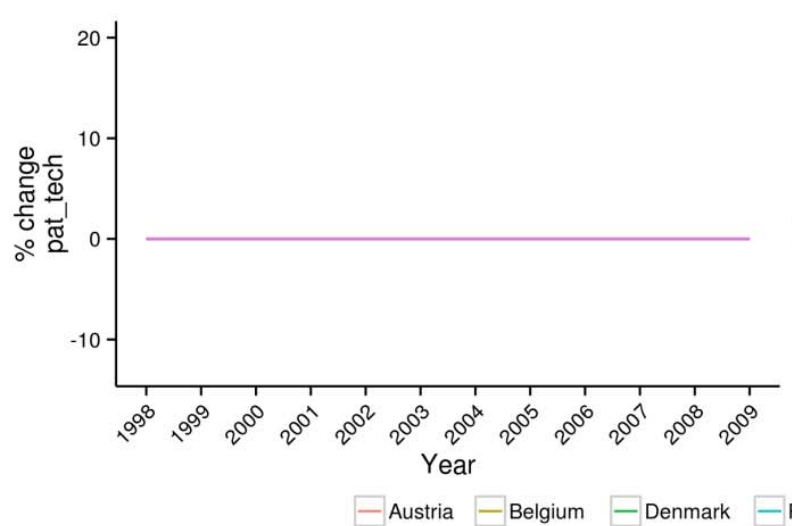

Repeated shock solar RD\&D and deployment

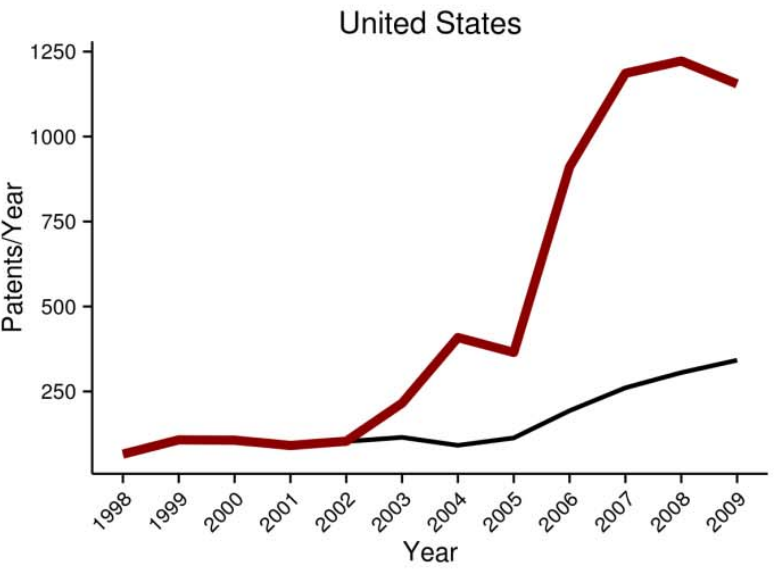

Germany

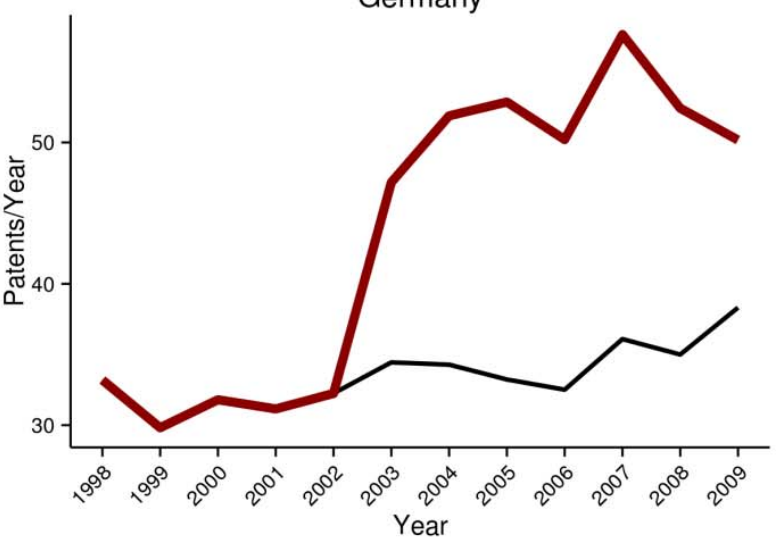

- prediction_new

Cross-border diffusion

from Germany

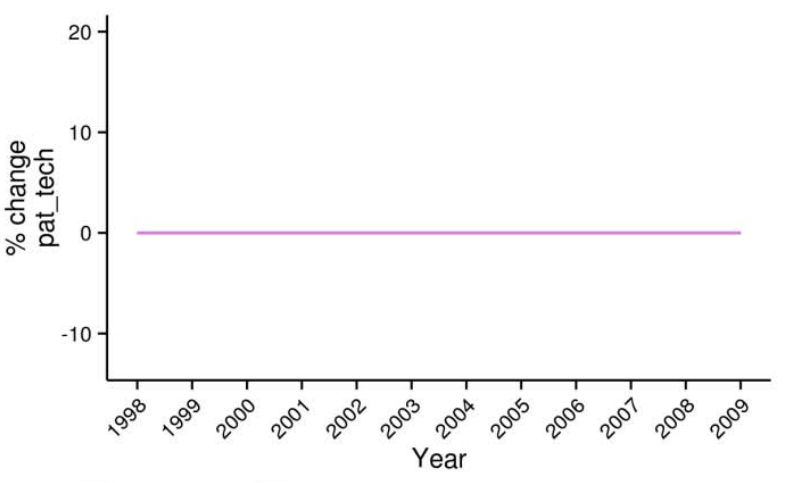




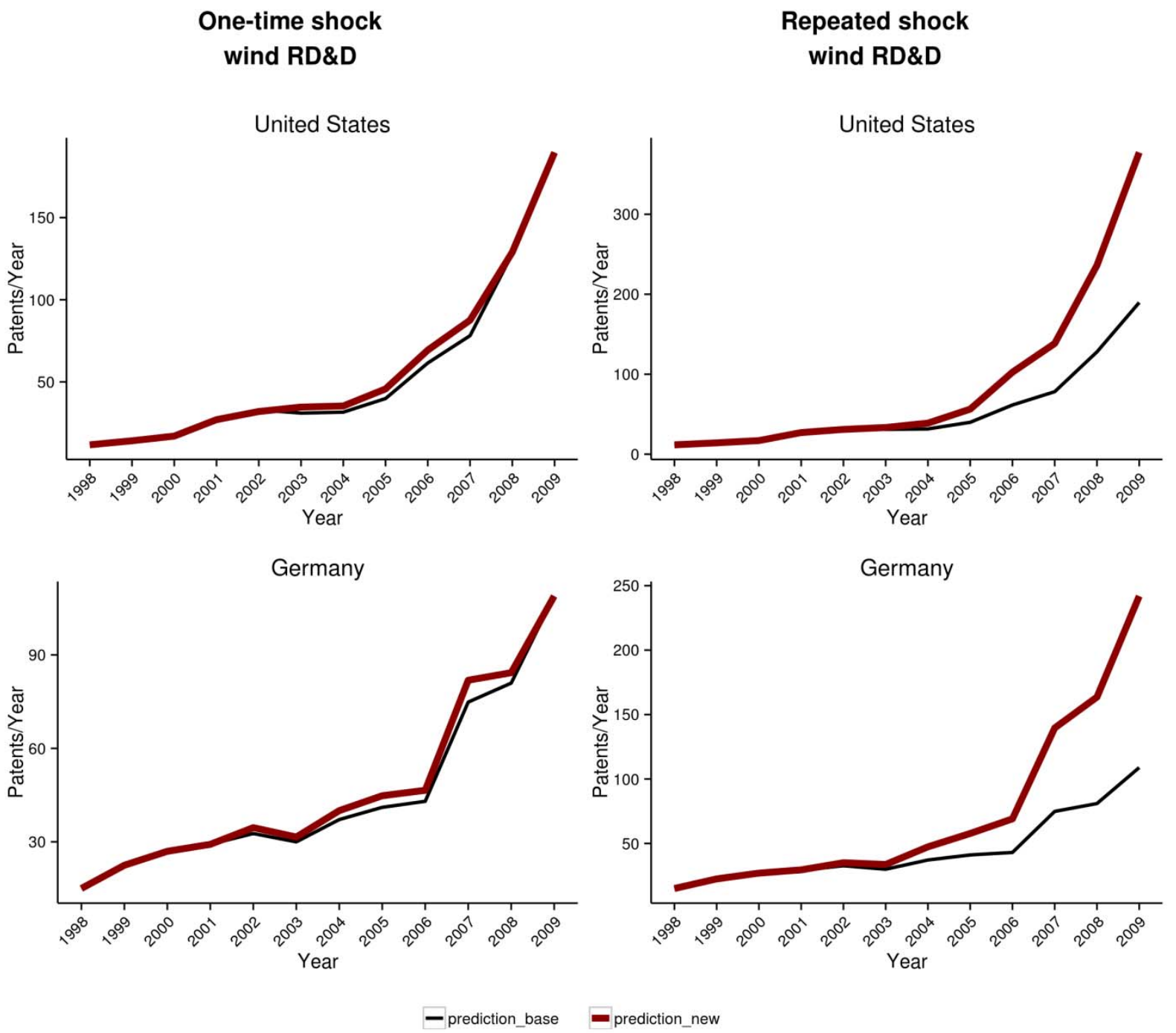

Cross-border diffusion from Germany
Cross-border diffusion from Germany
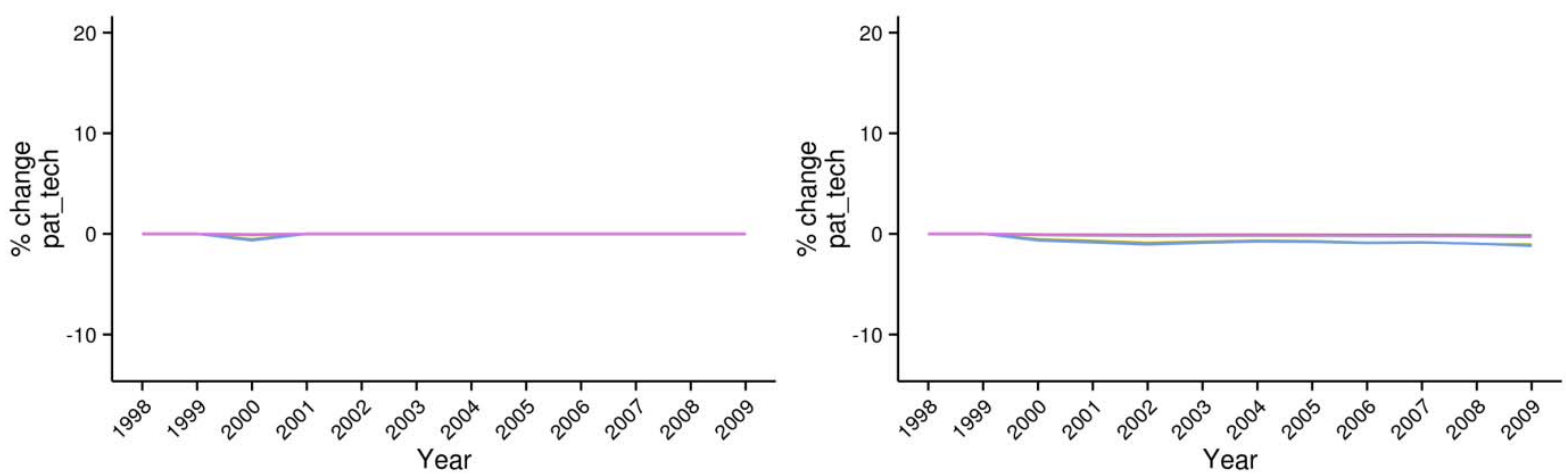

- Austria $\square$ Belgium $\square$ Denmark

France

Netherlands - Switzerland

32 


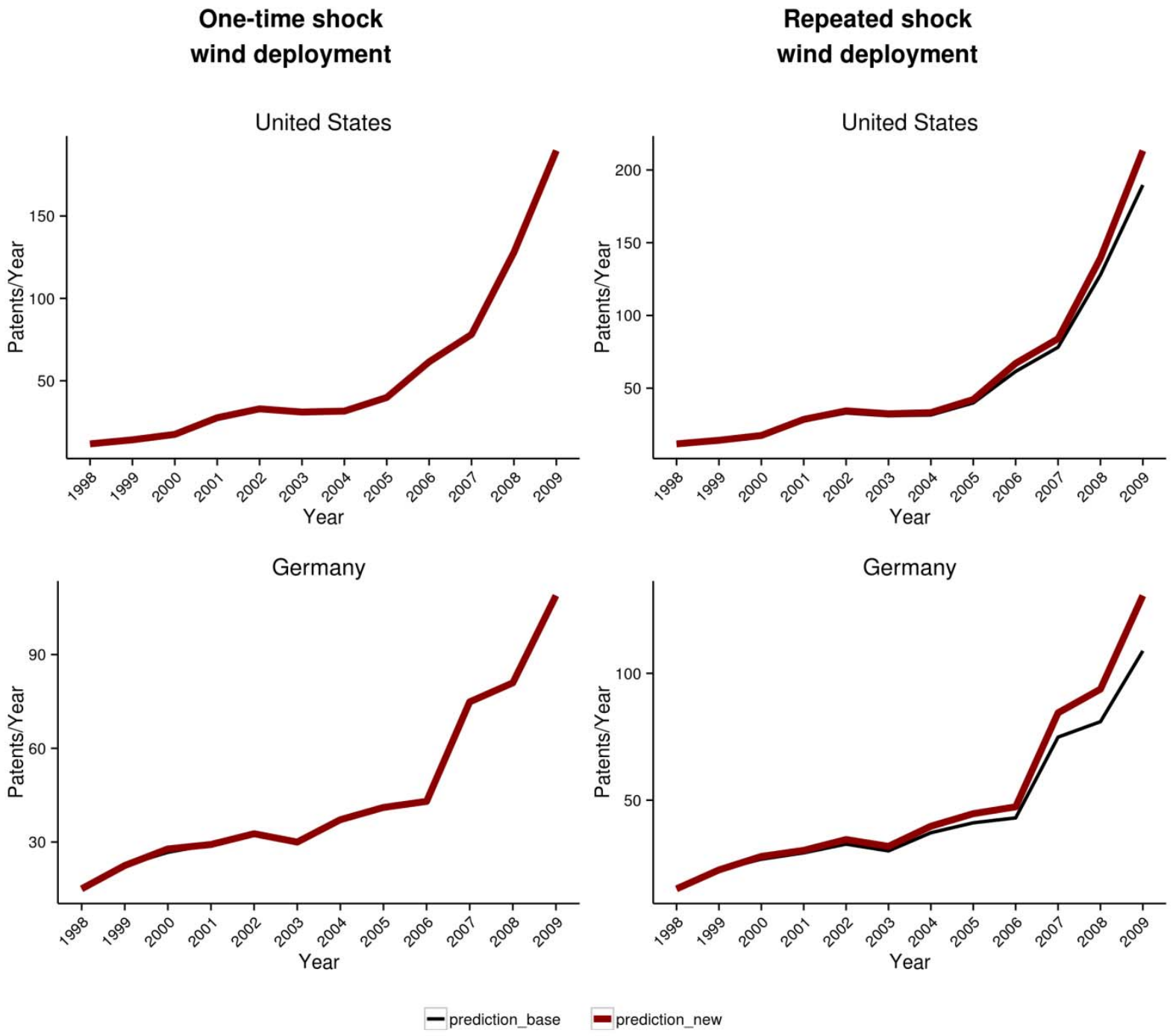

Cross-border diffusion from Germany
Cross-border diffusion from Germany
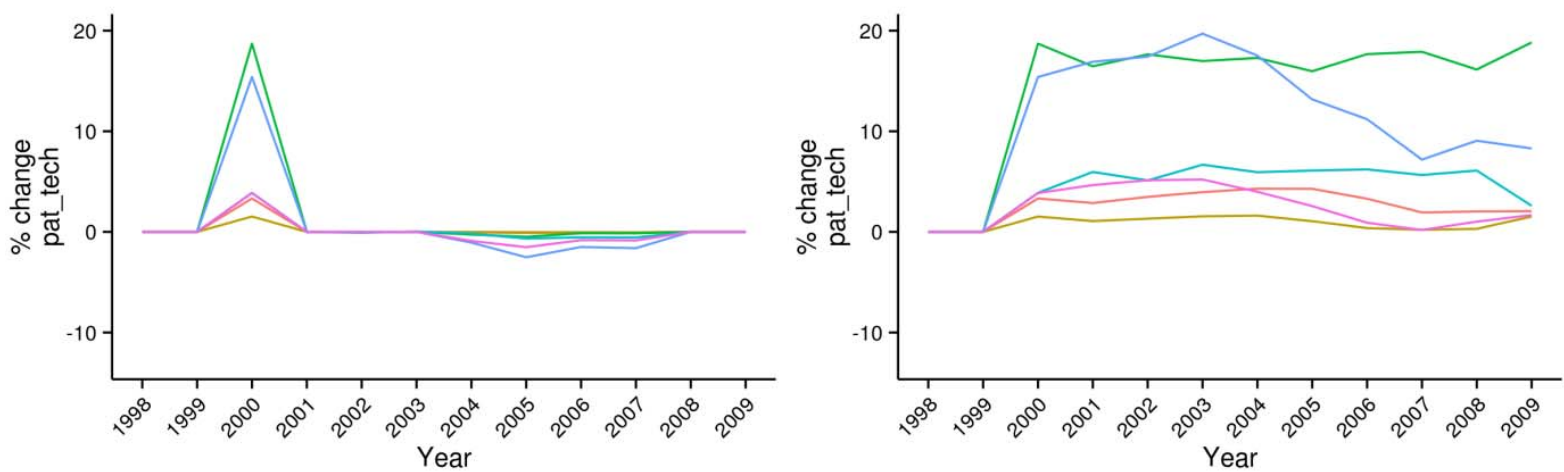

- Austria - Belgium -Denmark

-France

- Netherlands - Switzerland

33 
One-time shock wind RD\&D and deployment
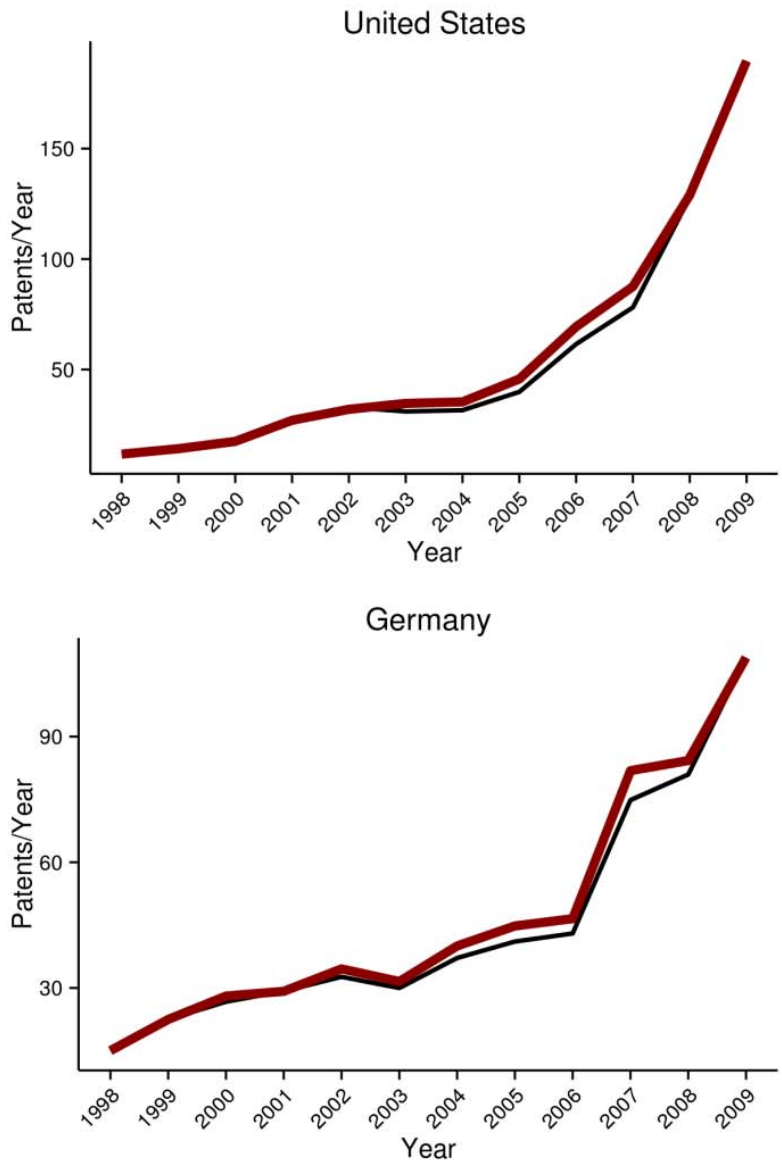

- prediction_base

Cross-border diffusion

from Germany

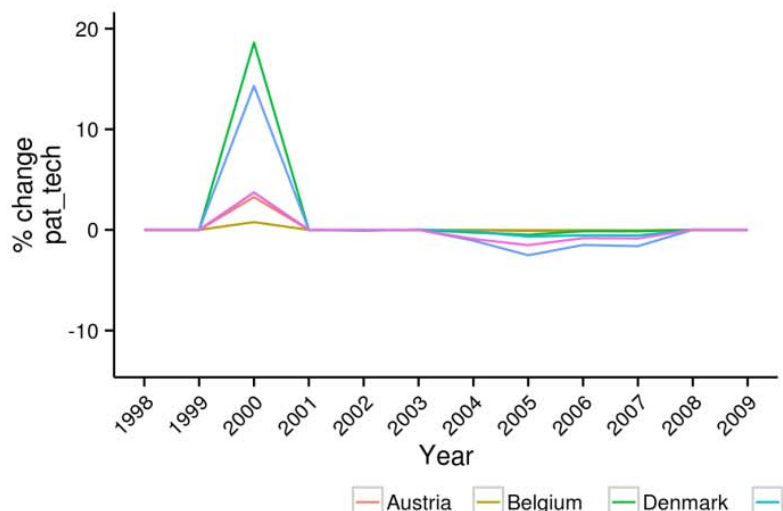

- Austria - Belgium - Denmark - France
Repeated shock

wind RD\&D and deployment

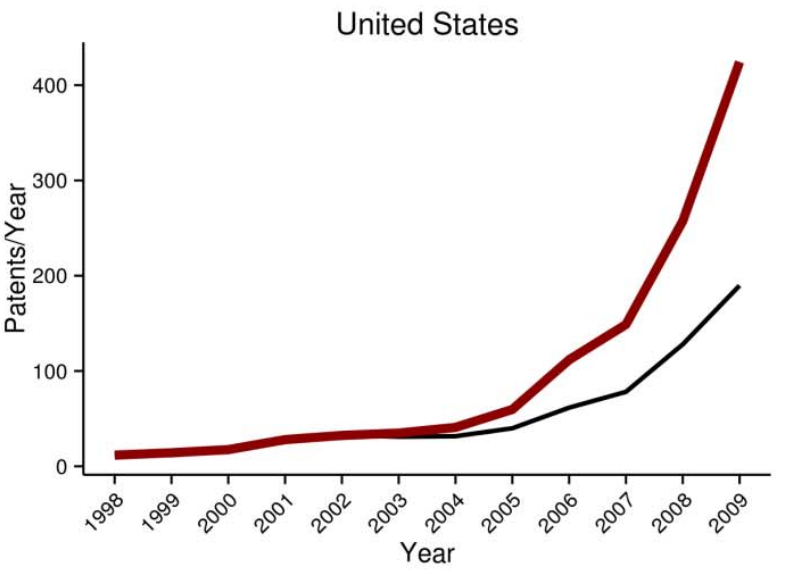

Germany

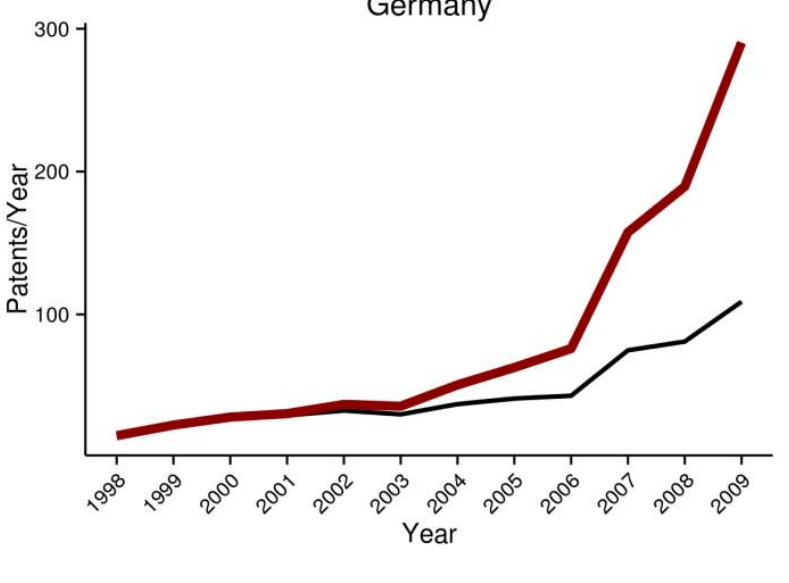

- prediction_new

Cross-border diffusion

from Germany

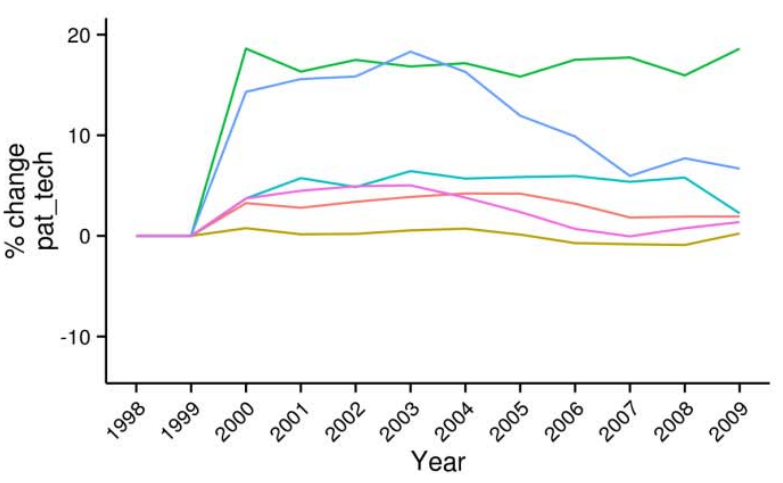




\section{RCA ranking regression}

Solar

\begin{tabular}{|c|c|}
\hline (Intercept) & 2.588 \\
\hline dep_solar_partsum2 lag1 & 0 \\
\hline dep_solar_partsum 3 lag1 & 0.01 \\
\hline dep_total_cumulated:rdd solar_dwdist & -0.107 \\
\hline pat_total logged & 0.241 \\
\hline rdd res rooted partsum 5 lag 3 & 0.075 \\
\hline rdd_res_squared_lag5:rdd_solar_logged_partsum4 & -0.018 \\
\hline rdd res_squared partsum4_lag2:rdd_solar_logged_partsum5 lag3 & -0.001 \\
\hline rdd res_squared partsum 5 lag2:rdd_solar_logged_partsum 5 lag3 & 0 \\
\hline rdd res_squared partsum5 lag3:rdd_solar_logged_partsum5 lag2 & -0.062 \\
\hline rdd res_squared partsum 5 lag3:rdd_solar_logged_partsum 5 lag3 & -0.019 \\
\hline rdd_solar_dwdist:rdd_solar_dwdistwces & -0.011 \\
\hline rdd_solar_dwdistwces:rdd_res_rooted_partsum 5 lag 3 & 0.061 \\
\hline rdd_solar_logged:rdd_res_squared_lag5 & -0.003 \\
\hline rdd_solar_logged:rdd_solar_logged_lag3 & 0.014 \\
\hline rdd_solar_logged:rdd_solar_logged_partsum1_lag2 & 0 \\
\hline rdd solar logged partsum2:rdd res squared partsum2 lag2 & -0.022 \\
\hline rdd_solar_logged_partsum2:rdd_res_squared_partsum4_lag1 & -0.001 \\
\hline rdd_solar_logged_partsum 3:rdd_res_squared_partsum4 lag2 & -0.013 \\
\hline rdd_solar_logged_partsum 5:rdd_res_squared_partsum 5 lag2 & -0.006 \\
\hline rdd_solar_logged_partsum 5:rdd_res_squared_partsum 5 lag 3 & -0.001 \\
\hline rdd solar logged partsum 5:rdd solar squared partsum3 lag1 & 0 \\
\hline rdd solar squared:rdd solar logged partsum 5 lag 3 & -0.021 \\
\hline
\end{tabular}




\section{Wind}

\begin{tabular}{|c|c|}
\hline (Intercept) & 2.603 \\
\hline continent dep wind & 0.028 \\
\hline continent dep wind:rdd res rooted lag3 & 0.025 \\
\hline continent dep_wind:rdd_res_rooted_partsum 1_lag2 & 0.018 \\
\hline continent dep_wind:rdd wind_partsum 5 lag 3 & 0.011 \\
\hline dep total:dep_wind dwdist & -0.009 \\
\hline dep_wind_dwdist:dep_total_partsum2 & -0.025 \\
\hline dep_wind_dwdist:dep_total_partsum5 & -0.003 \\
\hline dep_wind dwdist:dep_wind dwdistwces & -0.008 \\
\hline dep_wind_dwdist:rdd_wind_dwdist & -0.029 \\
\hline dep wind dwdist:rdd wind rooted lag5 & -0.033 \\
\hline dep_wind_dwdist:rdd_wind rooted_partsum 2 lag 3 & -0.008 \\
\hline dep_wind dwdist:rdd wind rooted_partsum5 & -0.052 \\
\hline dep_wind dwdistwces:dep_wind partsum5 lag3 & 0.02 \\
\hline pat total logged & 0.159 \\
\hline rdd_wind_dwdistwces:dep_wind_partsum 5 lag 3 & 0.009 \\
\hline rdd wind dwdistwces:rdd res lag 5 & 0.014 \\
\hline rdd wind_dwdistwces:rdd wind_partsum 5 lag2 & 0.009 \\
\hline rdd_wind_dwdistwces:rdd_wind_partsum 5 lag 3 & 0.028 \\
\hline rdd_wind logged_partsum2:rdd wind logged_partsum3 lag2 & -0.006 \\
\hline rdd_wind_logged_partsum3:rdd_wind_logged_partsum2 lag3 & -0.012 \\
\hline rdd wind logged partsum 3:rdd wind logged partsum 3 lag3 & -0.02 \\
\hline rdd wind logged partsum 5:rdd wind logged partsum 4 lag1 & -0.014 \\
\hline
\end{tabular}


One-time shock

solar RD\&D

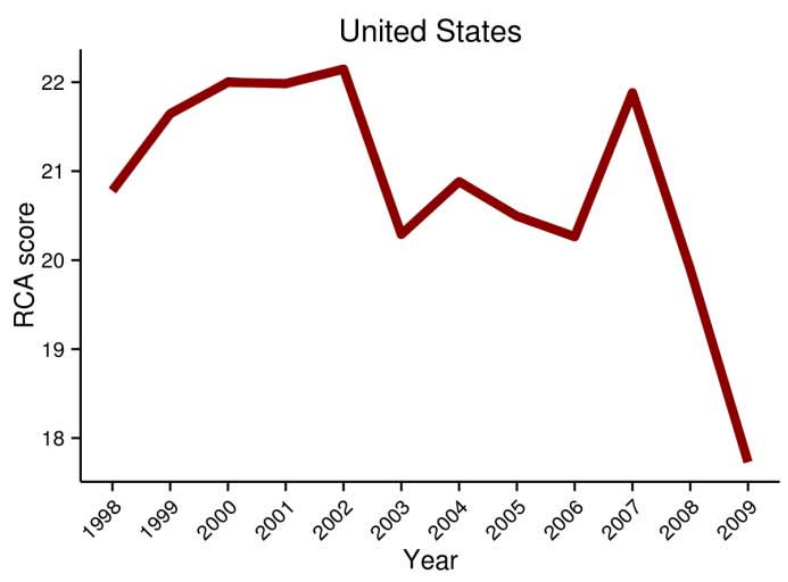

Germany

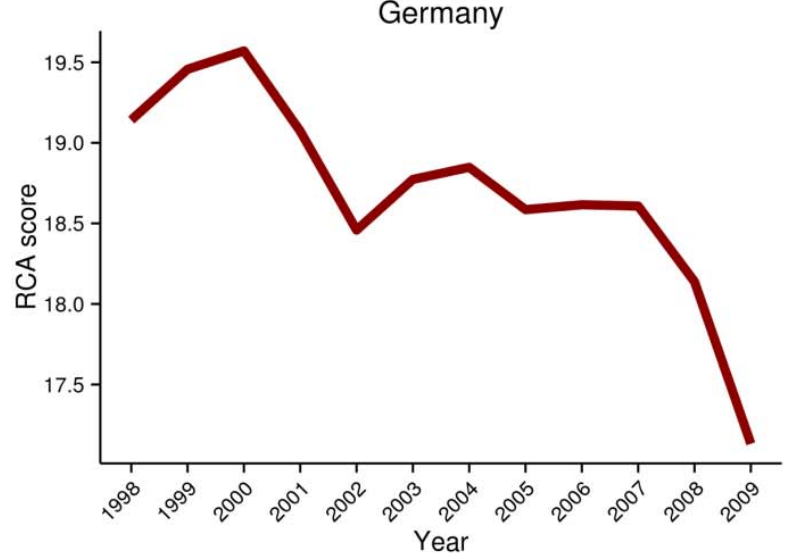

- prediction_base

Cross-border diffusion

from Germany

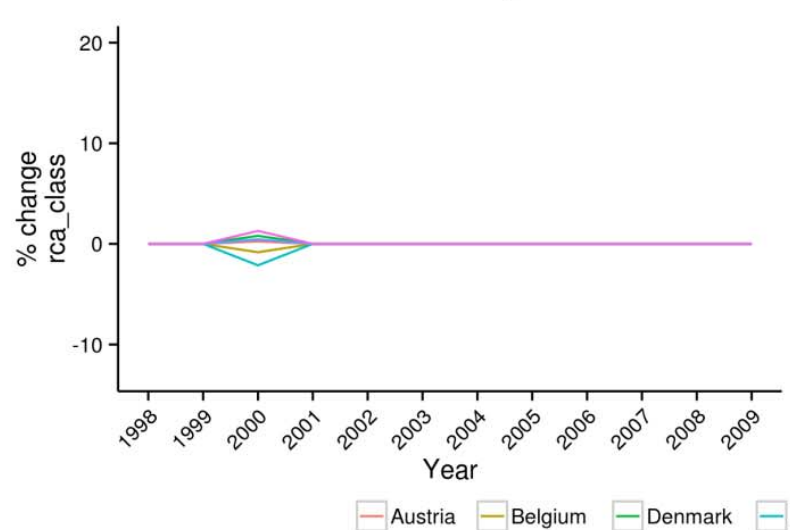

- Austria —Belgium —Denmark — France

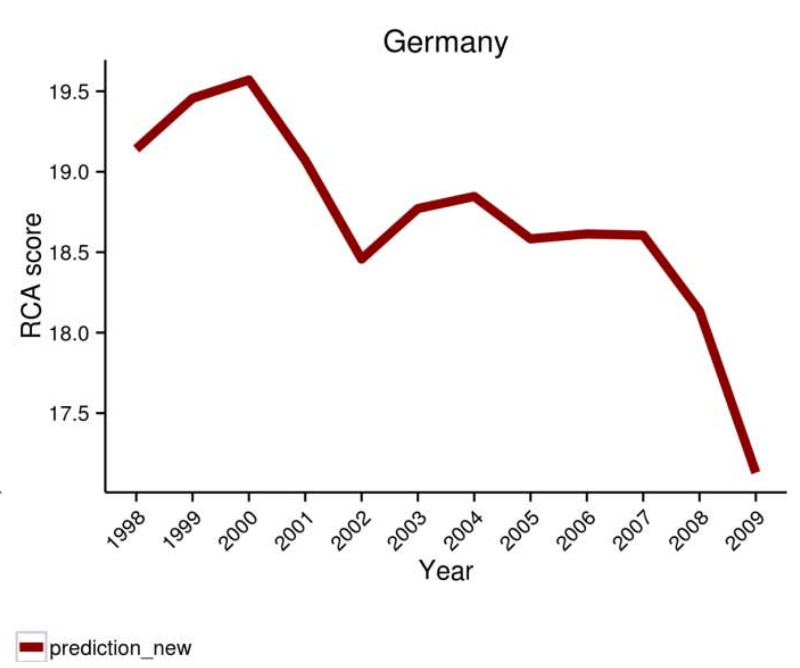

- prediction_new

Cross-border diffusion
from Germany

Cross-border diffusion
from Germany

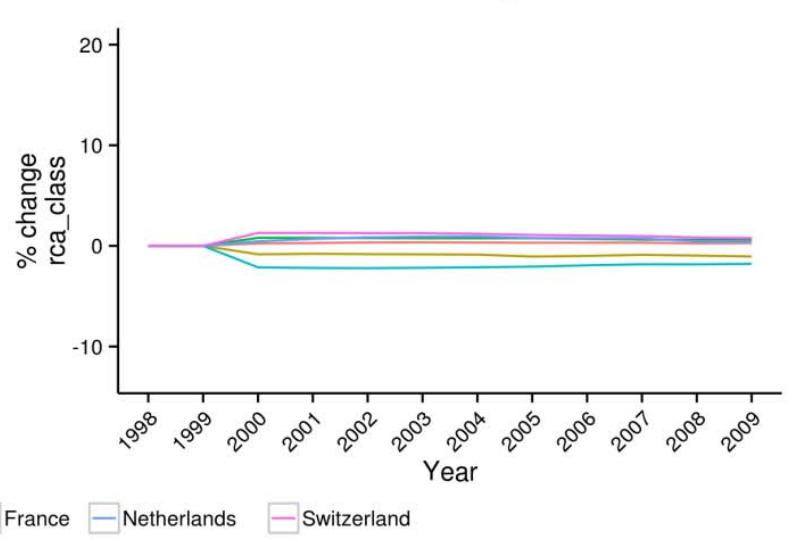

solar RD\&D

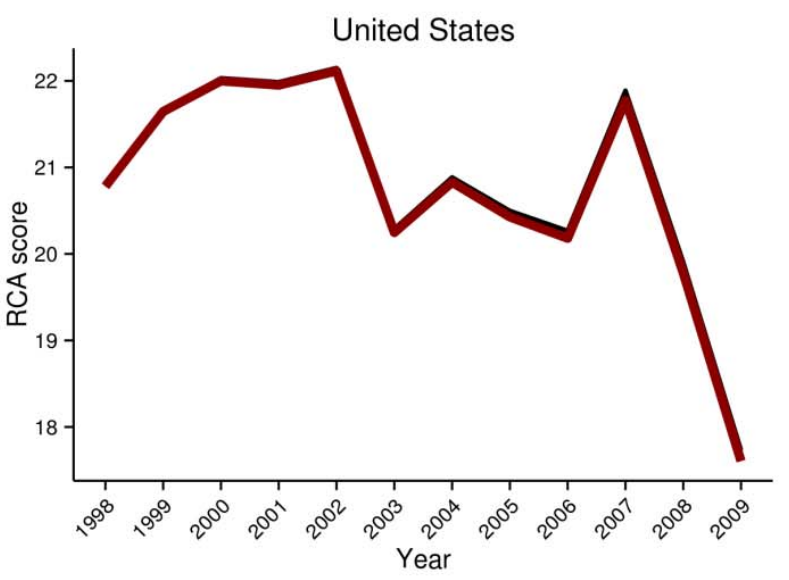

Repeated shock 
One-time shock

solar deployment
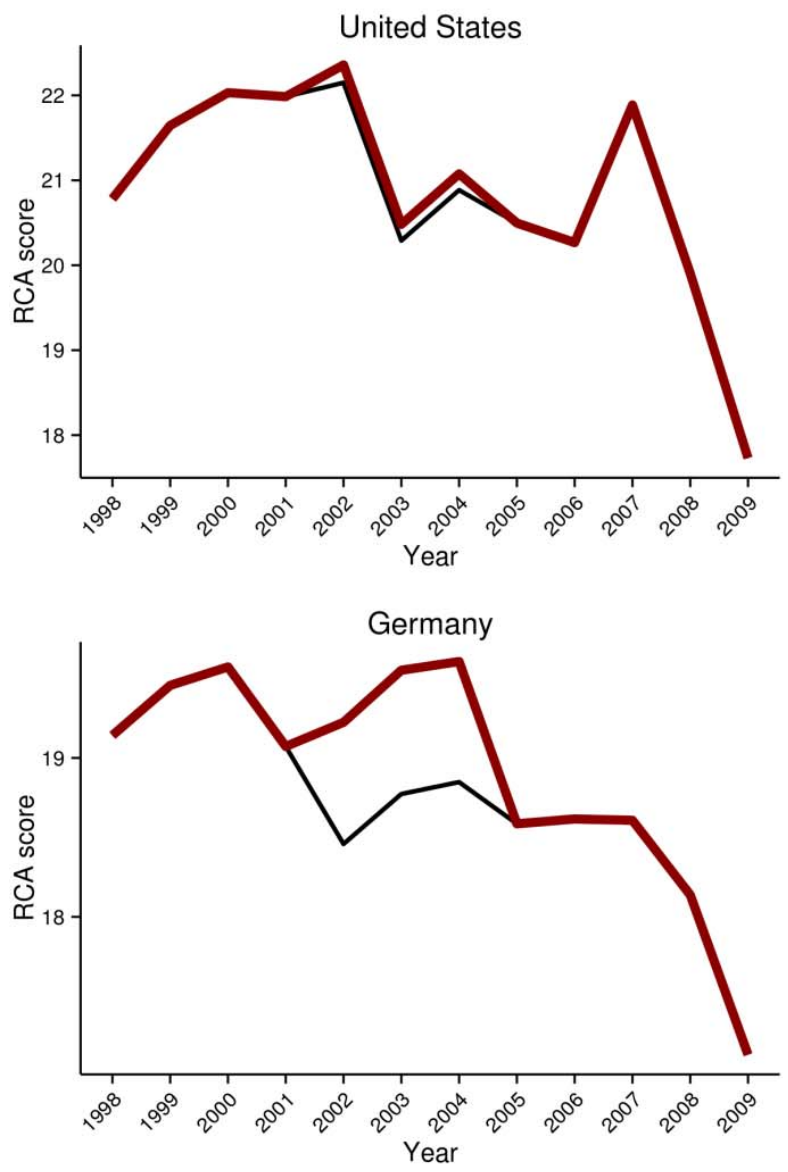

- prediction_base

Cross-border diffusion

from Germany

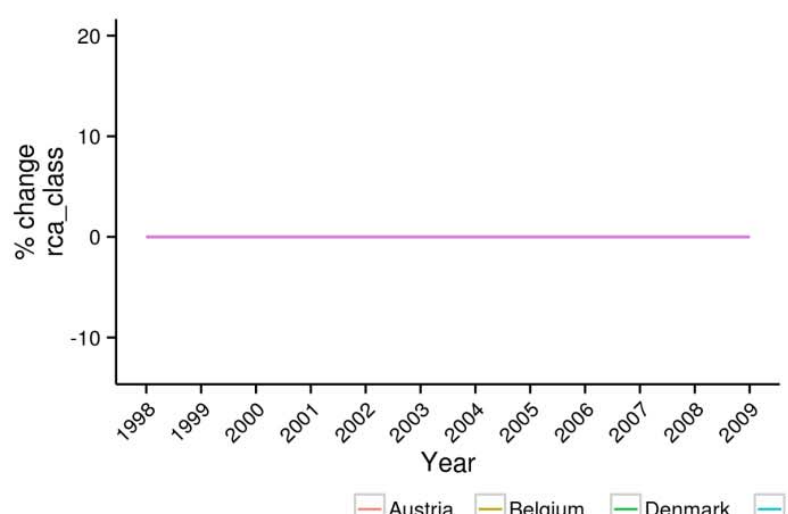

- Austria - Belgium - Denmark - France
Repeated shock

solar deployment
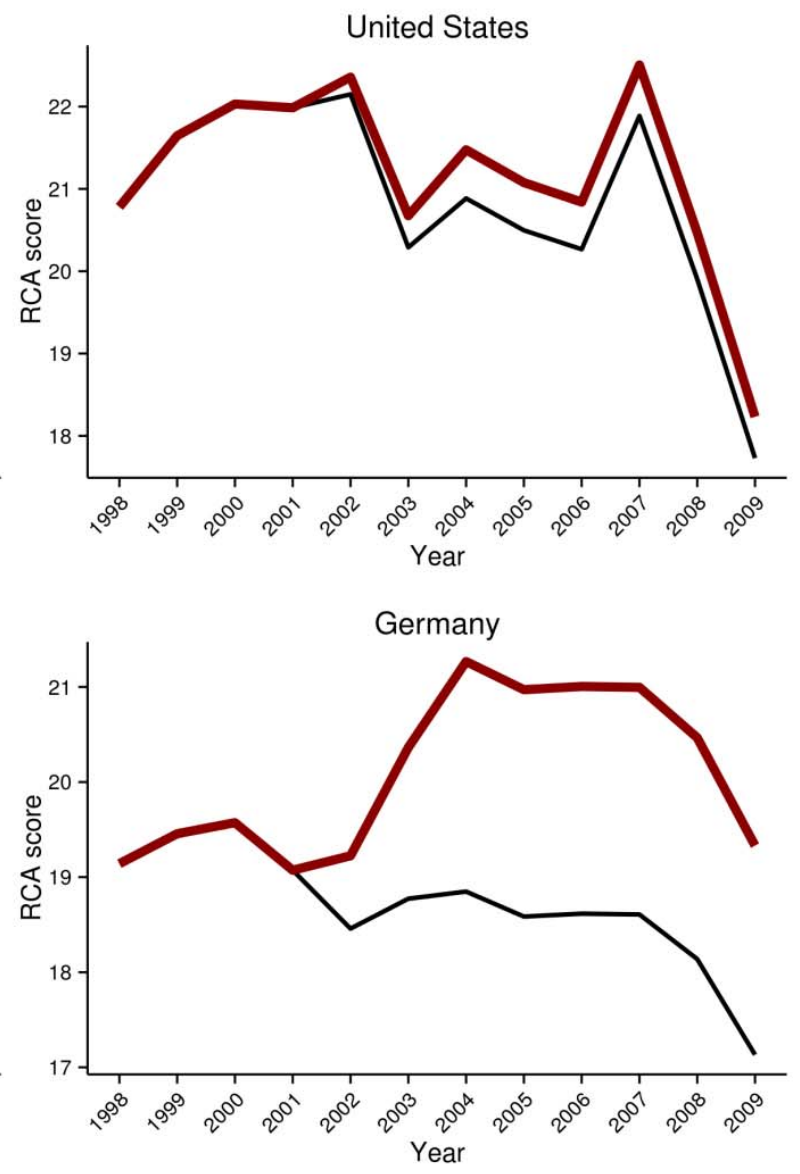

- prediction_new

Cross-border diffusion

from Germany

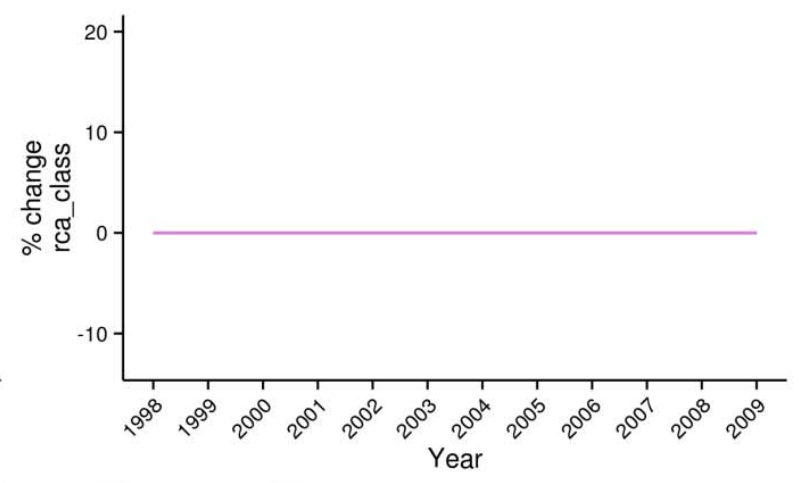


One-time shock solar RD\&D and deployment
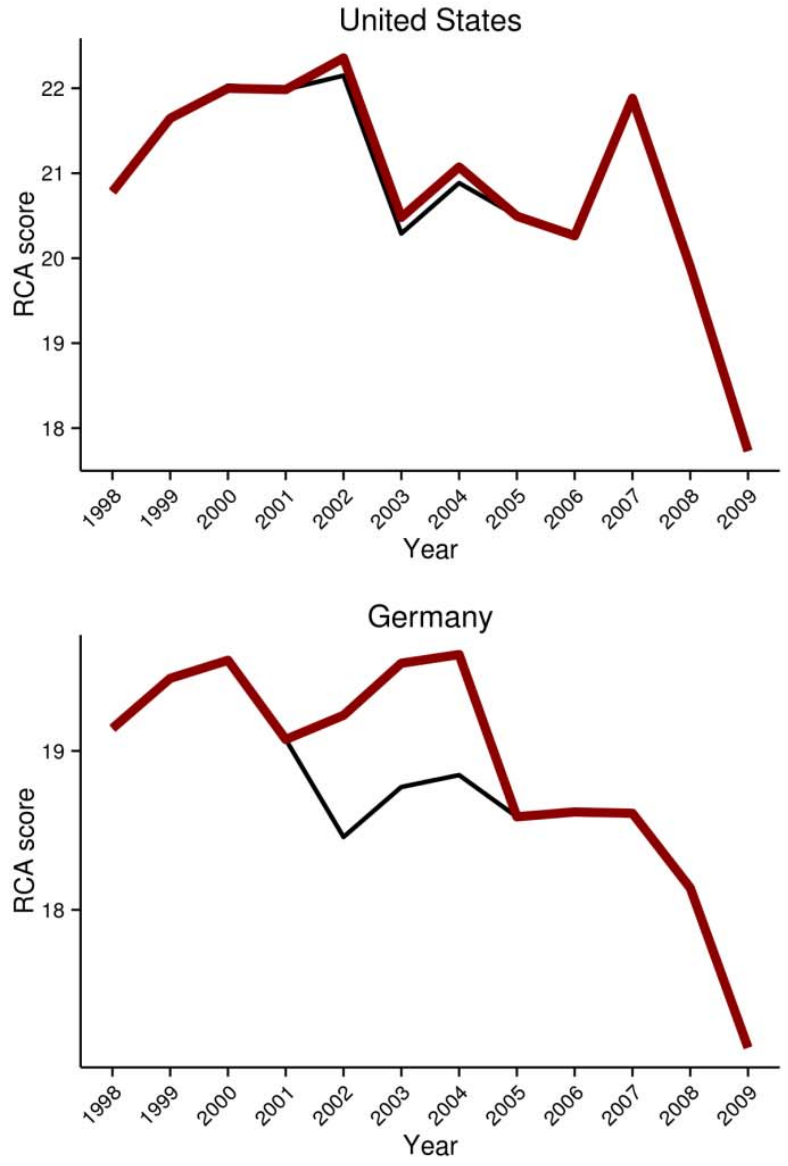

- prediction_base

Cross-border diffusion

from Germany

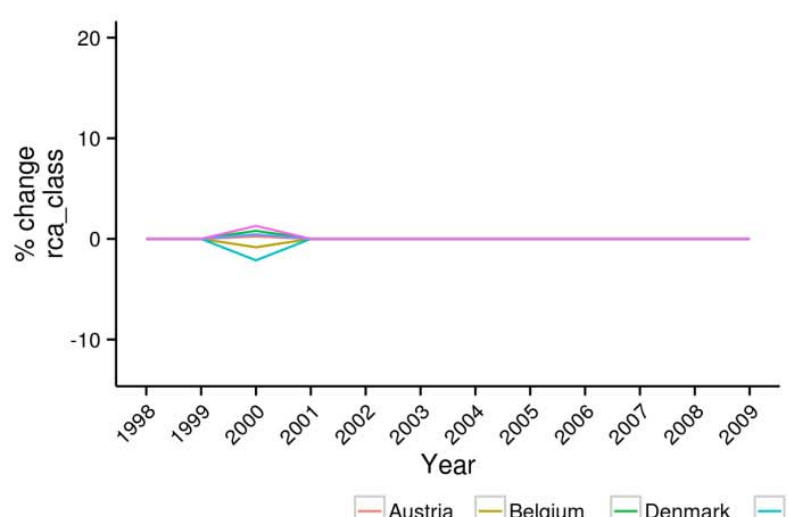

- Austria - Belgium - Denmark - France
Repeated shock solar RD\&D and deployment
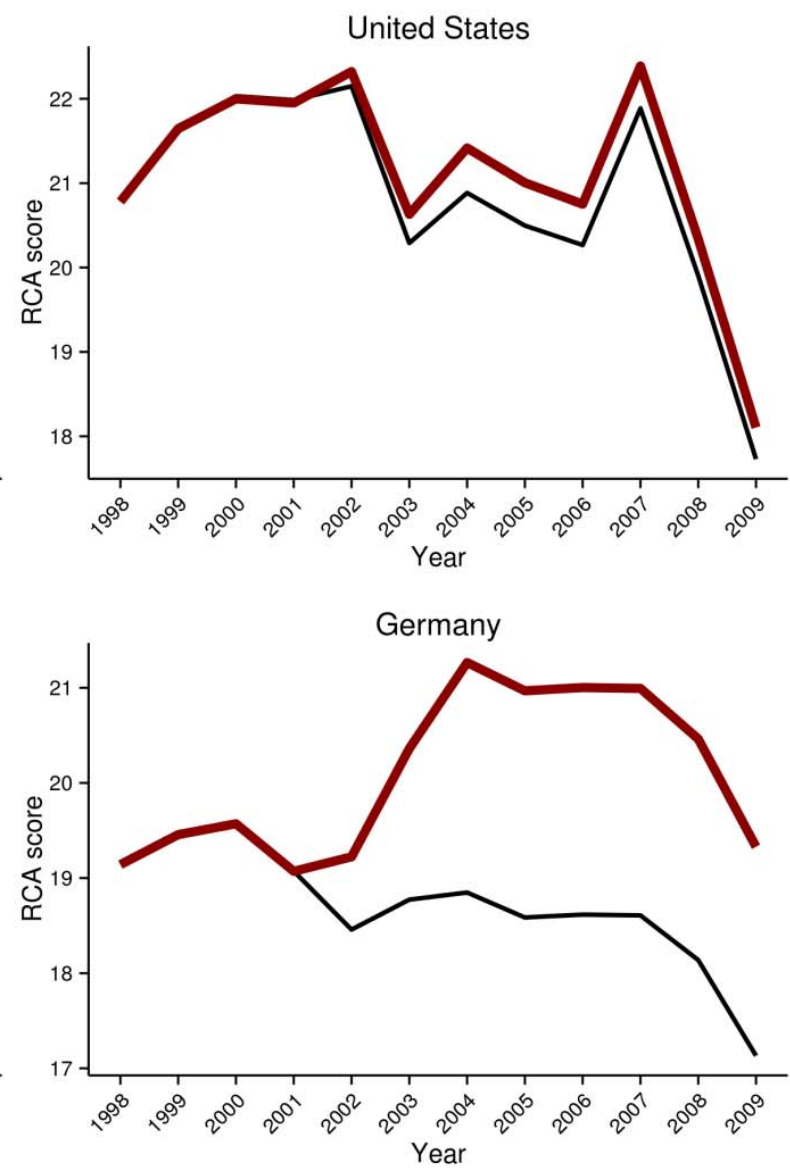

- prediction_new

Cross-border diffusion from Germany

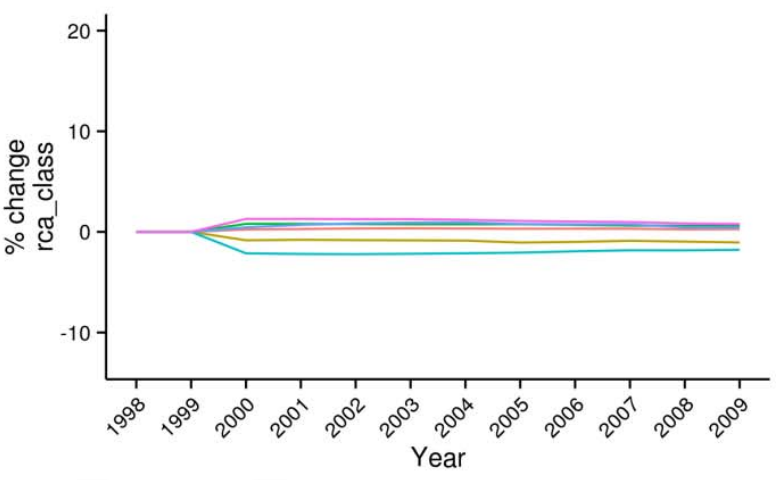


One-time shock

wind RD\&D
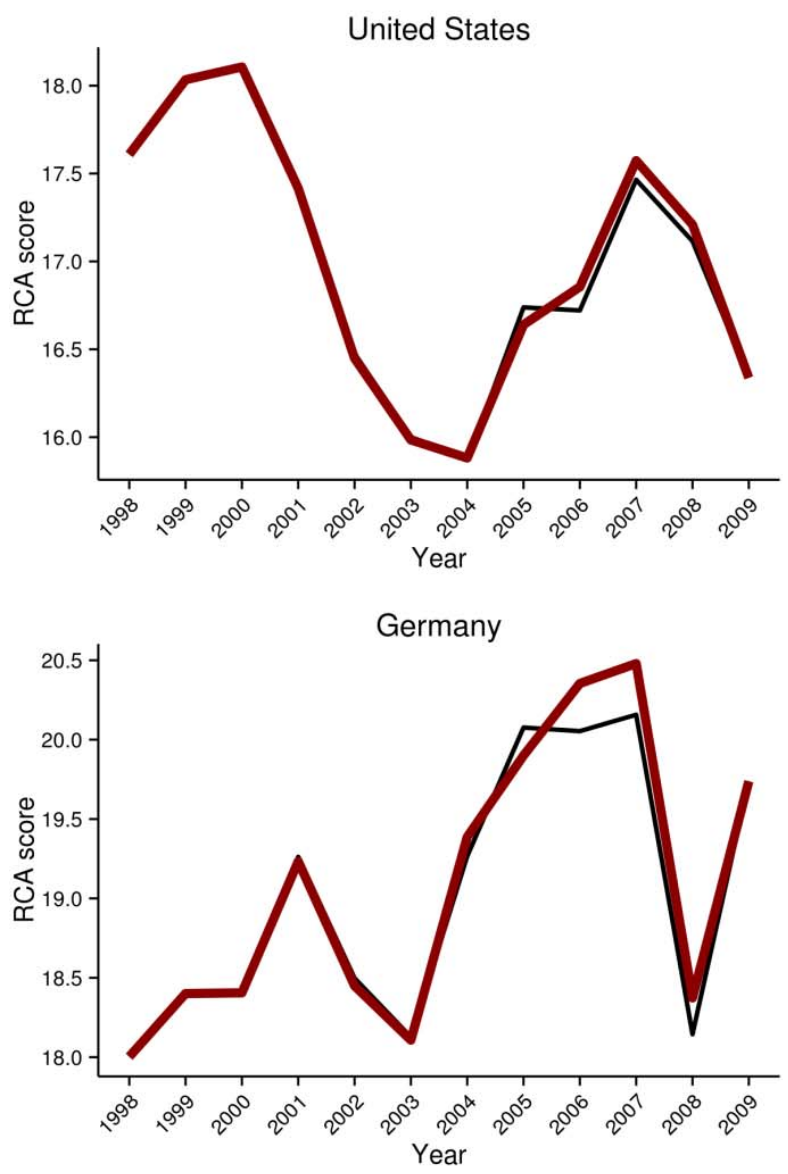

- prediction_base

Cross-border diffusion

from Germany

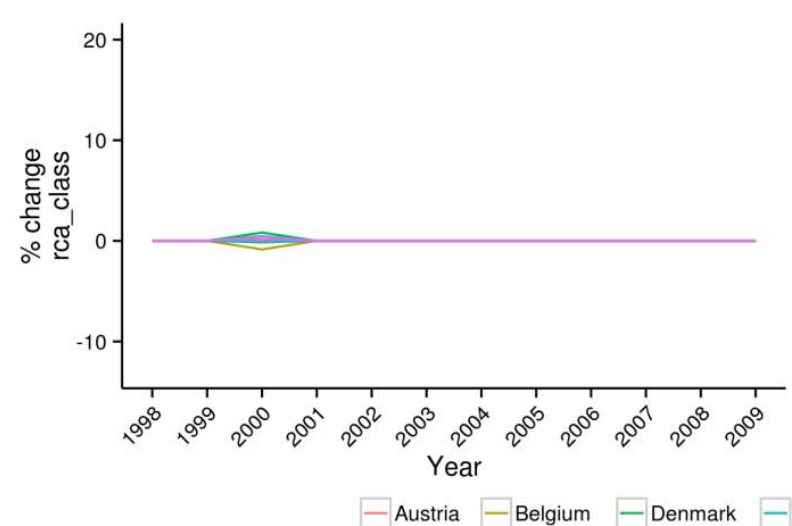

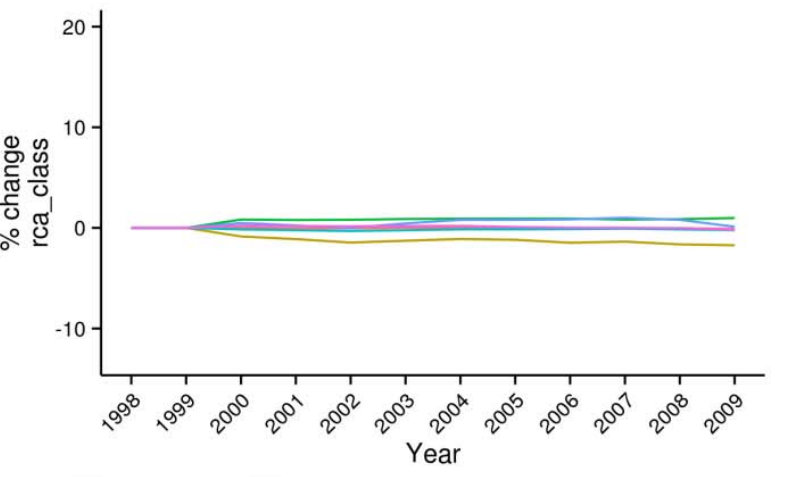

Repeated shock

wind RD\&D
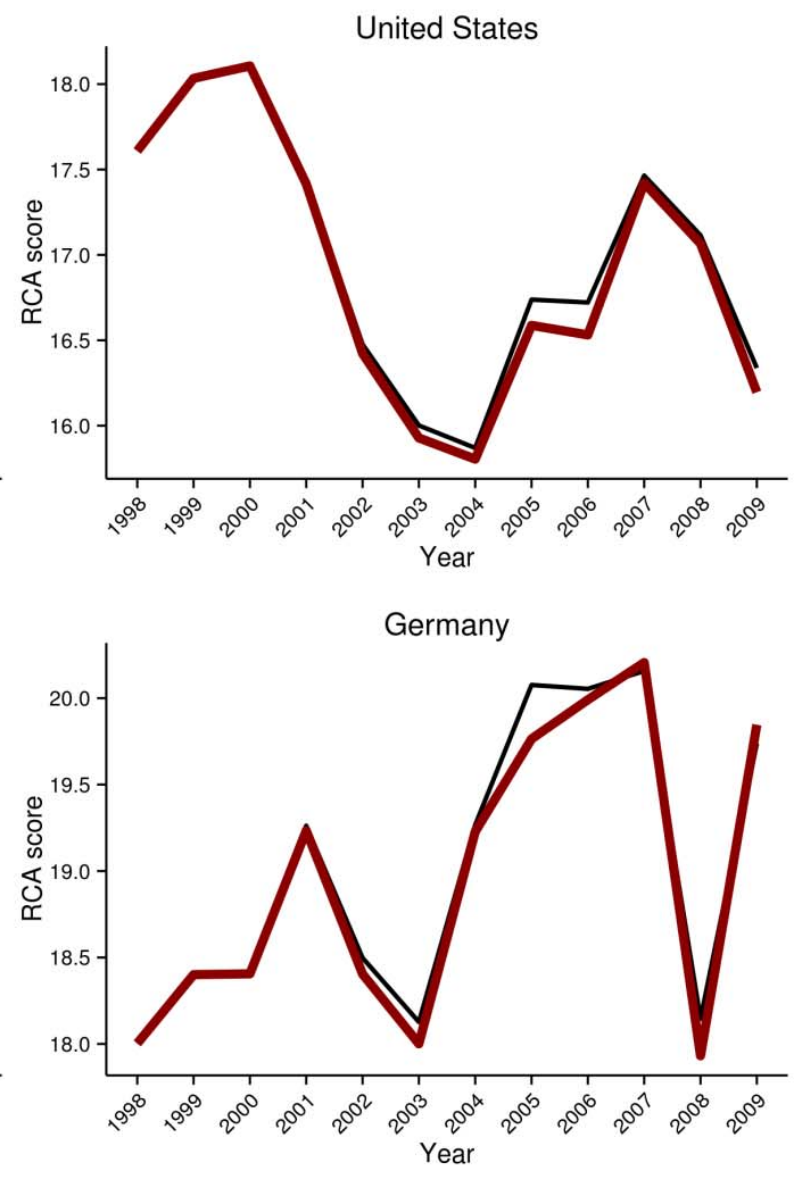

- prediction_new

Cross-border diffusion

from Germany

France $\square$ Netherlands $\square$ Switzerland 

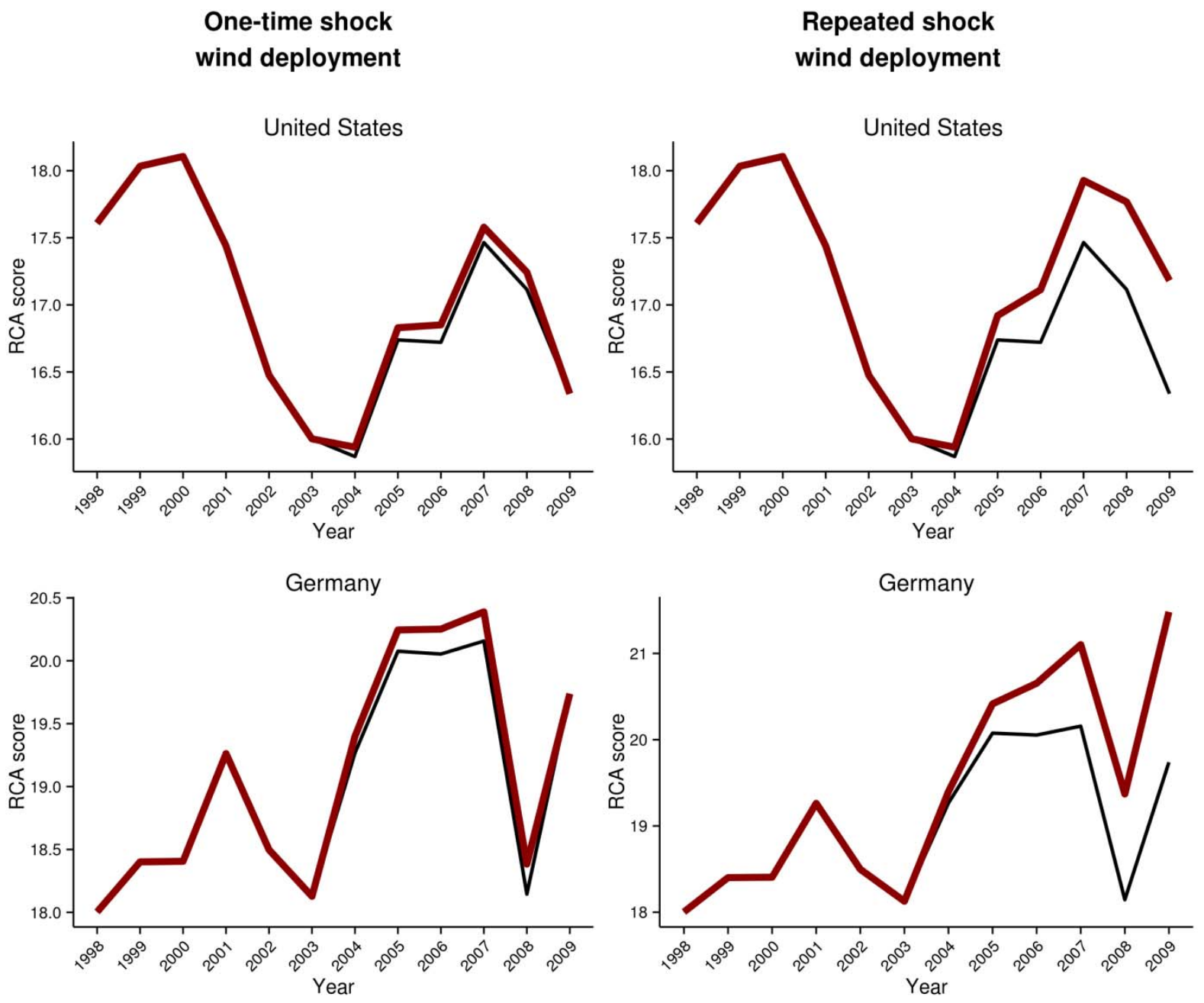

$$
\text { - prediction_base } \quad \text { prediction_new }
$$

Cross-border diffusion from Germany
Cross-border diffusion from Germany
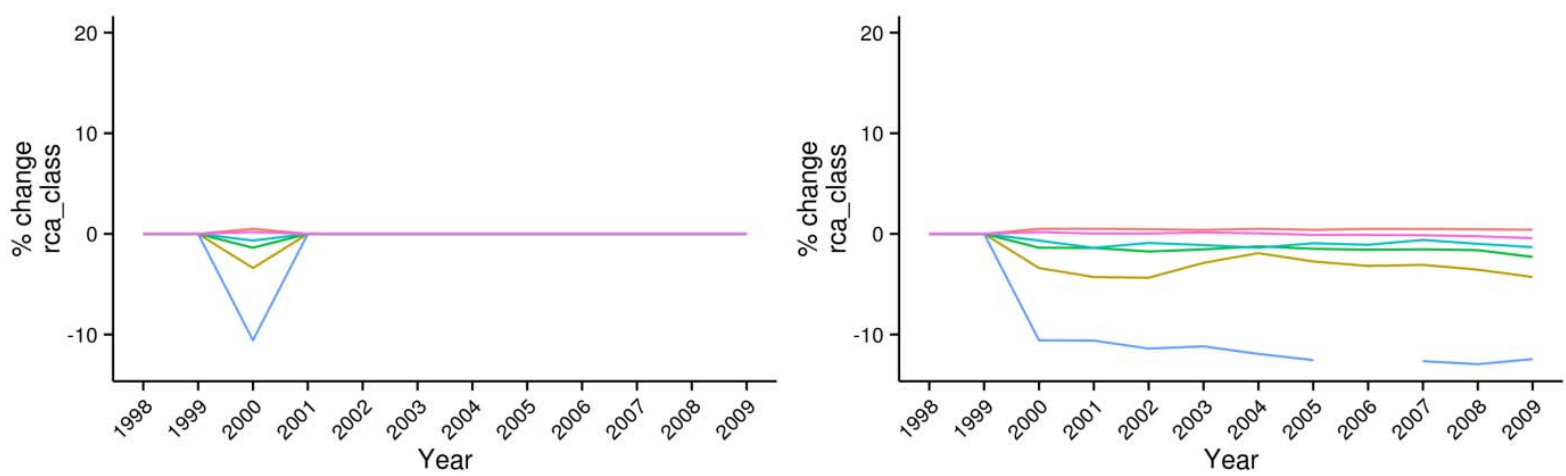

- Austria $\square$ Belgium -Denmark — France

- Netherlands $\square$ Switzerland

41 

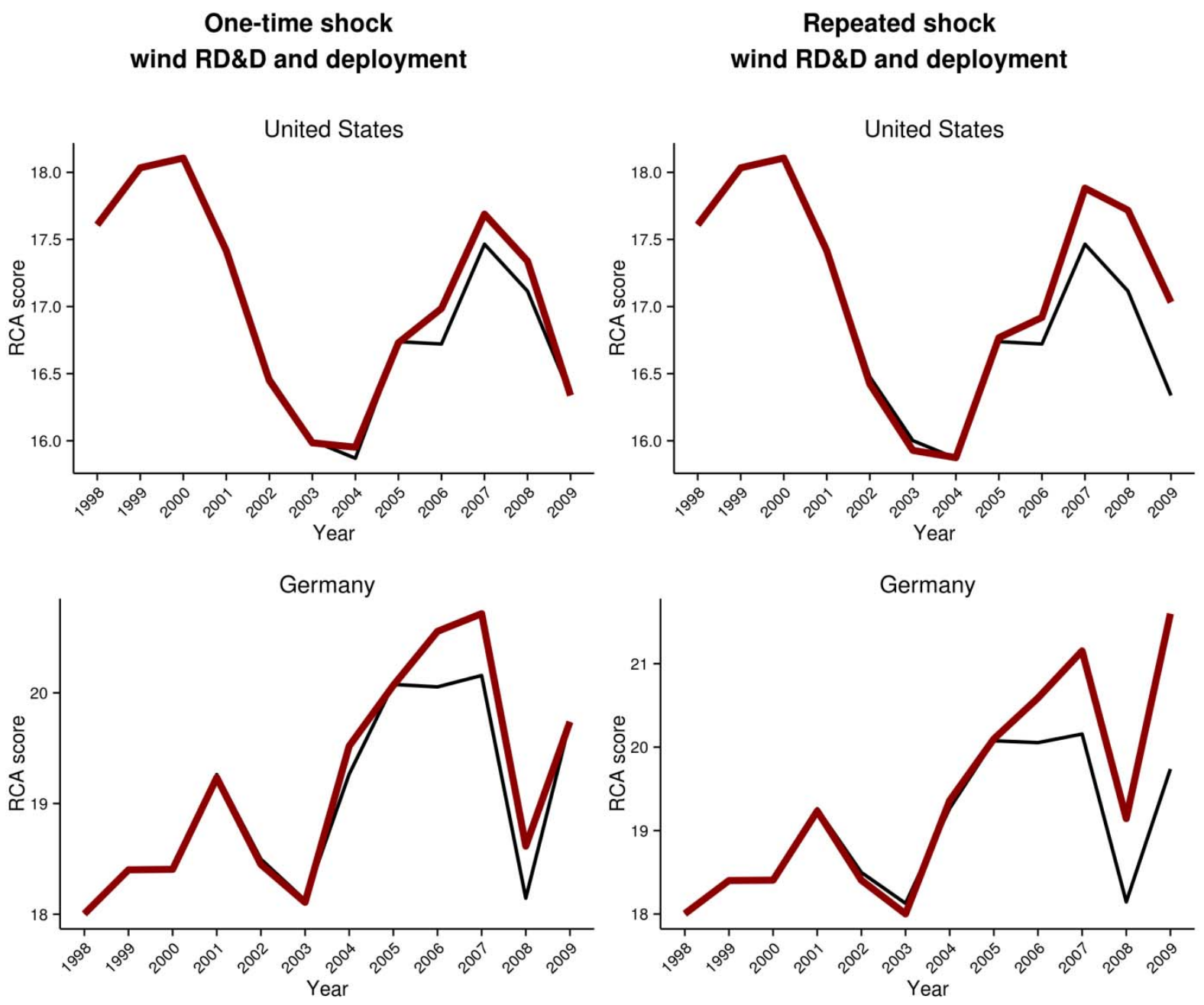

$$
\text { - prediction_base } \quad \text { prediction_new }
$$

Cross-border diffusion from Germany
Cross-border diffusion from Germany
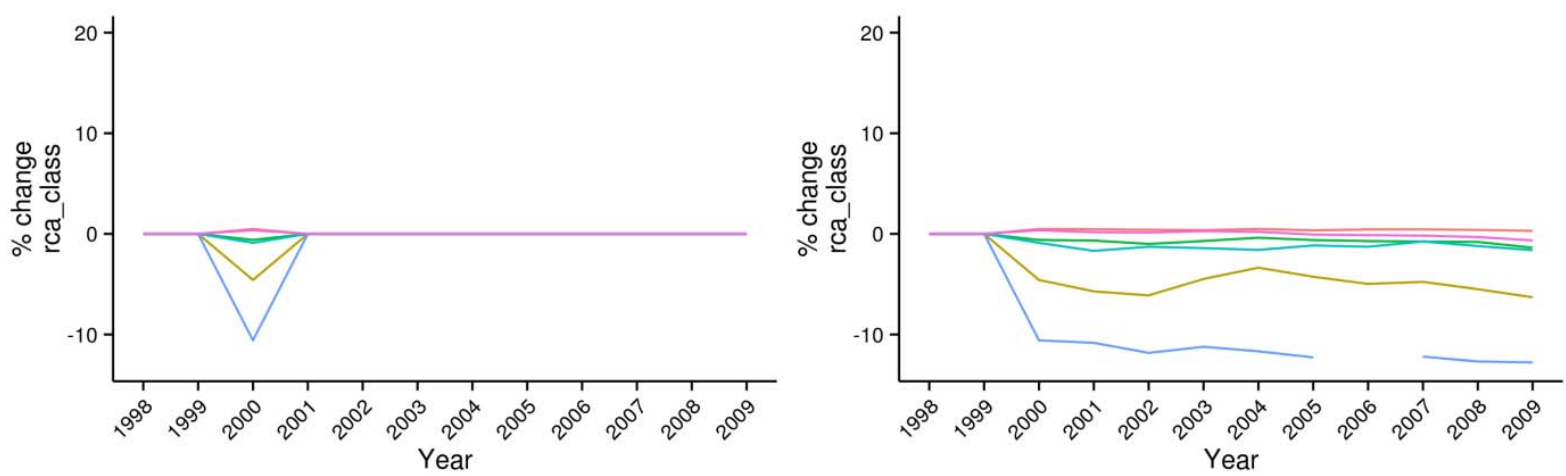

- Austria $\square$ Belgium -Denmark — France

- Netherlands $\square$ Switzerland

42 